\title{
Comparison of results from two 3D hydrodynamic models with field data: internal seiches and horizontal currents
}

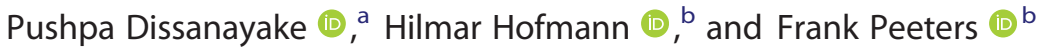

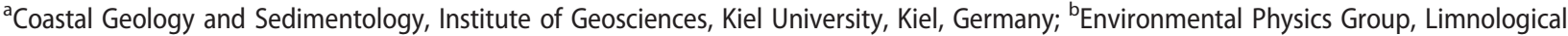 \\ Institute, University of Konstanz, Konstanz, Germany
}

\begin{abstract}
Model skills of two 3D hydrodynamic models, ELCOM and Delft3D, were assessed by simulating internal seiches and surface currents and comparing the results with field data in Upper Lake Constance, Germany. Both models were set up using the same horizontal and vertical discretisation and forced by a horizontally resolved wind field. Model simulations were carried out during a stable stratification period in summer. Oscillations of the simulated and the measured isotherms in Lake Überlingen (north basin of Upper Lake Constance) indicated the existence of a Kelvin-type wave with a period of $84 \mathrm{~h}$. The major wave pattern in period and amplitude was consistent between the simulations and the measurements, whereas discrepancies appeared in the phase match. The measured and the simulated vertical velocity structure in the middle of the main basin of Upper Lake Constance showed occurrence of a Poincaré-type wave with a $14 \mathrm{~h}$ period. Major oscillations of the velocity structure were captured by both models, and the agreement between the simulations and the measurements was higher in deep layers than in near-surface layers. Model prediction of the near-surface velocities as well as the surface circulation pattern was more accurate under high current velocities during strong winds than under weak winds. This study concluded that both ELCOM and Delft3D were significantly skilled at simulating internal wave motions and surface currents, and there was no significant difference in reproducing the measured lake dynamics between ELCOM and Delft3D.
\end{abstract}

\section{KEYWORDS}

ELCOM; Delft3D; horizontal and vertical current field; internal waves; temperature stratification; Upper Lake Constance

\section{Introduction}

Internal basin scale oscillations (internal seiches) are a prominent feature during the stratified period in most lakes and are the major source of currents and kinetic energy in the deeper parts of the water column (Wüest and Lorke 2003, Appt et al. 2004). In the surface water of stratified lakes, currents due to seiches are usually larger than in the deep water because the extent of the deep water layer (hypolimnion) is typically larger than that of the surface layer (epilimnion; Appt et al. 2004). The currents in the surface layer not only result from internal seiches but are additionally generated by direct wind forcing (Imberger and Patterson 1990). The wind-driven surface circulation patterns are more sensitive to the instantaneous wind speed and wind direction than the currents due to internal seiching. Currents from seiching are mainly related to the amplitudes of the seiches, which are determined by the integrated wind energy input into lakes and to the seiching periods, which depend on the density stratification and the morphometry of the basin (Wüest and Lorke 2003).
The stratification of many lakes is predominantly determined by the vertical temperature distribution (Wüest and Lorke 2003), whereas salinity in most cases only contributes to stratification during low temperatures, close to $4{ }^{\circ} \mathrm{C}$ (Ollinger 1999). The thermal stratification of lakes varies seasonally because of seasonal changes in the surface heat fluxes (Boyce et al. 1989), especially during summer stratification characterized by a large density gradient in the thermocline, which suppresses turbulence. Therefore, vertical transport of momentum by turbulent mixing through the thermocline is small and contributes little to the kinetic energy in the deep water of lakes (Wüest and Lorke 2003). However, during the stratification period, wind forcing can generate internal seiches (Antenucci et al. 2000, Appt et al. 2004). These seiches can efficiently transfer wind energy introduced at the lake surface into the deep water of lakes and thus affect physical, biological, and ecological processes in the deep water, such as turbulence, vertical mixing, and the structure of the benthic boundary layer, and thus also the exchange of nutrients and gases at the water-sediment interface (Umlauf and

CONTACT Pushpa Dissanayake pushpa.dissanayake@ifg.uni-kiel.de 
Lemmin 2005). The simulation of the current field and vertical mixing in lakes requires not only reliable wind fields, a coupling of the lake surface to wind forcing, and vertical turbulent mixing, but also data on meteorology for the estimation of surface heat fluxes and a model capable of simulating thermal stratification and baroclinic motions.

Different 3D numerical models have been employed to investigate hydrodynamics in a wide range of lakes, such as ELCOM in Lake Ontario (North America; Rao et el. 2009, Huang et al. 2010b), Lake Como (Europe; Laborde et al. 2010), Lake Constance (Europe; Appt et al. 2004), and Lake Biwa (Japan; Shimizu et al. 2007); FVCOM in Lake Erie (Niu et al. 2015) and Lake Huron (North America; Nguyen et al. 2014); POM in Lake Victoria (East Africa; Song et al. 2004) and Lake Michigan (North America; Beletsky et al. 1997); GETM in Lake Alpnach (Europe; Becherer and Umlauf 2011); Delft3D in Lake Geneva (Europe; Razmi et al. 2013, 2014) and Upper Lake Constance (Wahl and Peeters 2014); and a new hydrodynamic model in Lake Biwa (Koue et al. 2018). In the present study we adopted 2 commonly applied numerical models, the Estuary Lake and Coastal Ocean Model (ELCOM, version 2.2: Hodges and Dallimore 2006) and Delft3D-FLOW (herein referred to as Delft3D, version 4.03.01; Deltares 2014), to simulate the baroclinic dynamics in Upper Lake Constance. Both modelling codes are available in open source and are being continuously improved by optimizing the existing processes. However, the heat flux estimation remains the same in the updated versions of these models. Therefore, similar results leading to similar conclusions can be expected, even using the latest version of these models in the present study. The fundamental numerical scheme of ELCOM is based on the Tidal, Residual, Intertidal Mudflat (TRIM) approach (Casulli and Cheng 1992) with modifications for accuracy, scalar conservation, numerical diffusion, and implementation of a mixed-layer turbulence closure (Hodges and Dallimore 2006). Delft3D uses a finite differencing approach with an alternating direction implicit (ADI) numerical scheme (Stelling 1984), and the turbulence closure is based on the eddy-viscosity concept (Uittenbogaard et al. 1992). ELCOM in combination with CAEDYM has been one of the most commonly employed model systems to address coupled hydrodynamic-ecological questions in lakes. Although support for ELCOMCAEDYM ended, it was recently reestablished in a new model environment (AEM3D: http://www.hydronumerics. com.au/software/aquatic-ecosystem-model-3d). In the Delft3D modelling suite, the basic module is Delft3DFLOW, in which hydrodynamics are calculated and used as input to the other modules (e.g., Delft3D-WAVE: short wave propagation; Delft3D-SED: sediment transport; Delft3D-ECO: ecological modelling; D-WQ: water quality). Both models use the hydrostatic assumption and the nonhydrostatic pressure to estimate scaler transport. In this study, ELCOM and Delft3D were employed using the hydrostatic assumption, which reduces the computational cost and is appropriate for coarse-grid models simulating slow, long-term period motions.

These 2 models have been used for different numerical experiments in Upper Lake Constance (Appt et al. 2004, Wahl and Peeters 2014). Appt et al. (2004) used ELCOM to simulate the baroclinic basin-scale wave motions in Upper Lake Constance during autumn. Comparison of the model results and the field data indicated that the period and amplitude of waves agreed with the field data, but differences in the phase agreement were observed. This study used only measured temperature profiles for the comparisons of basin-scale waves. Wahl and Peeters (2014) simulated Upper Lake Constance using Delft3D and investigated the effects of climate change on the stratification and the deep-water renewal. Validation with a temperature profile in the middle of the lake revealed that the model can adequately simulate the thermal stratification over decades. Delft3D has been used to simulate current patterns under different wind forcings (Lake Geneva: Razmi et al. 2013) and evaluate the sensitivity of residence time for different wind forcings (Lake Geneva: Razmi et al. 2014). The present study is the first to compare the performance of Delft3D and ELCOM using time series of temperature, current, and drifter data.

Few studies have directly compared different 3D hydrodynamic models and field data in lakes (e.g., Beletsky et al. 1997, Huang et al. 2010b). POM and DIECAST models were used by Beletsky et al. (1997) to simulate internal waves in Lake Michigan. The POM results were more sensitive to the grid resolution than those in DIECAST. Huang et al. (2010b) compared the performance of 3 hydrodynamic models (POM, CANDIE, and ELCOM) with field data to simulate the seasonal and the synoptic variability of the thermal structure and circulation in Lake Ontario. The results showed that all 3 models reproduced the observed major spatial patterns of the mean temperatures. ELCOM predicted higher magnitudes in velocities while the other 2 models more closely agreed with the observations. The performance of Delft3D in predicting the lake hydrodynamics, however, has not yet been compared with the other $3 \mathrm{D}$ models. The model comparison here focused on the performance of models ELCOM and Delf3D in simulating $3 \mathrm{D}$ hydrodynamics, which is the basis for the ecosystem 
or water quality models, and comparing the results with field data.

The main objective of the present study was to investigate the ability of two 3D models (ELCOM and Delft3D) to simulate stratification, baroclinic dynamics, and surface currents in large lakes using the example of Upper Lake Constance. Simulated results were compared with temperature and current profiles at 2 mooring locations and to the velocity data from a series of drifter experiments to show the agreement between simulated and measured surface currents and circulation patterns.

We provide a description of the study area and the field data, followed by a comparison of the 2 hydrodynamic models employed in this study and an explanation of the statistical parameters used for the analysis of the model results and the measured data. We then compare simulated results of the 2 models with the field data and discuss the simulated and measured dynamics in the lake to formulate conclusions.

\section{Study area and field data}

This study was conducted on Upper Lake Constance, located at the southern boundary of Germany (Fig. 1). Upper Lake Constance has a surface area of $\sim 470 \mathrm{~km}^{2}$, a maximum depth of $252 \mathrm{~m}$, a mean depth of $\sim 100 \mathrm{~m}$, and a mean width of $\sim 9 \mathrm{~km}$ (Appt et al. 2004). Upper
Lake Constance consists of 2 main basins, Lake Überlingen (maximum depth $\sim 145 \mathrm{~m}$ ) and the main basin, connected at the Sill of Mainau where the water depth is $\sim 100 \mathrm{~m}$. The 2 main wind directions are SW-W and NE. Wind from SW-W prevails particularly during strong events spanning 1-7 d with a frequency of 2-9 d per month (Huss and Stranz 1970). Additionally, a day-night wind pattern also exists in the central basin of the lake and is particularly pronounced between the inflows of Rotach and Argen (Fig. 1). In Upper Lake Constance, the water level fluctuates seasonally by $\sim 2.5 \mathrm{~m}$; maximum water levels typically occur during summer months as a result of melting ice and precipitation in the Alpine catchment.

Precise bathymetric maps of Upper Lake Constance were produced between 2014 and 2015 using multibeam echosounding and LiDAR-techniques (http:// www.tiefenschaerfe-bodensee.info/Projekt/). The entire lake bathymetry is gridded on $10 \times 10 \mathrm{~m}$ cells while the nearshore area $(<10 \mathrm{~m}$ water depth) is additionally surveyed on higher resolution $3 \times 3 \mathrm{~m}$ grids. A time series of vertical temperature profiles was measured with a thermistor chain moored at station S1 (Fig. 1) in Lake Überlingen from 15 July to 31 August 2009. The chain was equipped with 28 thermistors (TR-1060 from RBR Ltd., Kanata, ON, Canada) placed between 0.8 and $125 \mathrm{~m}$ water depth with vertical spacing increasing with increasing water depth. The thermistors sampled

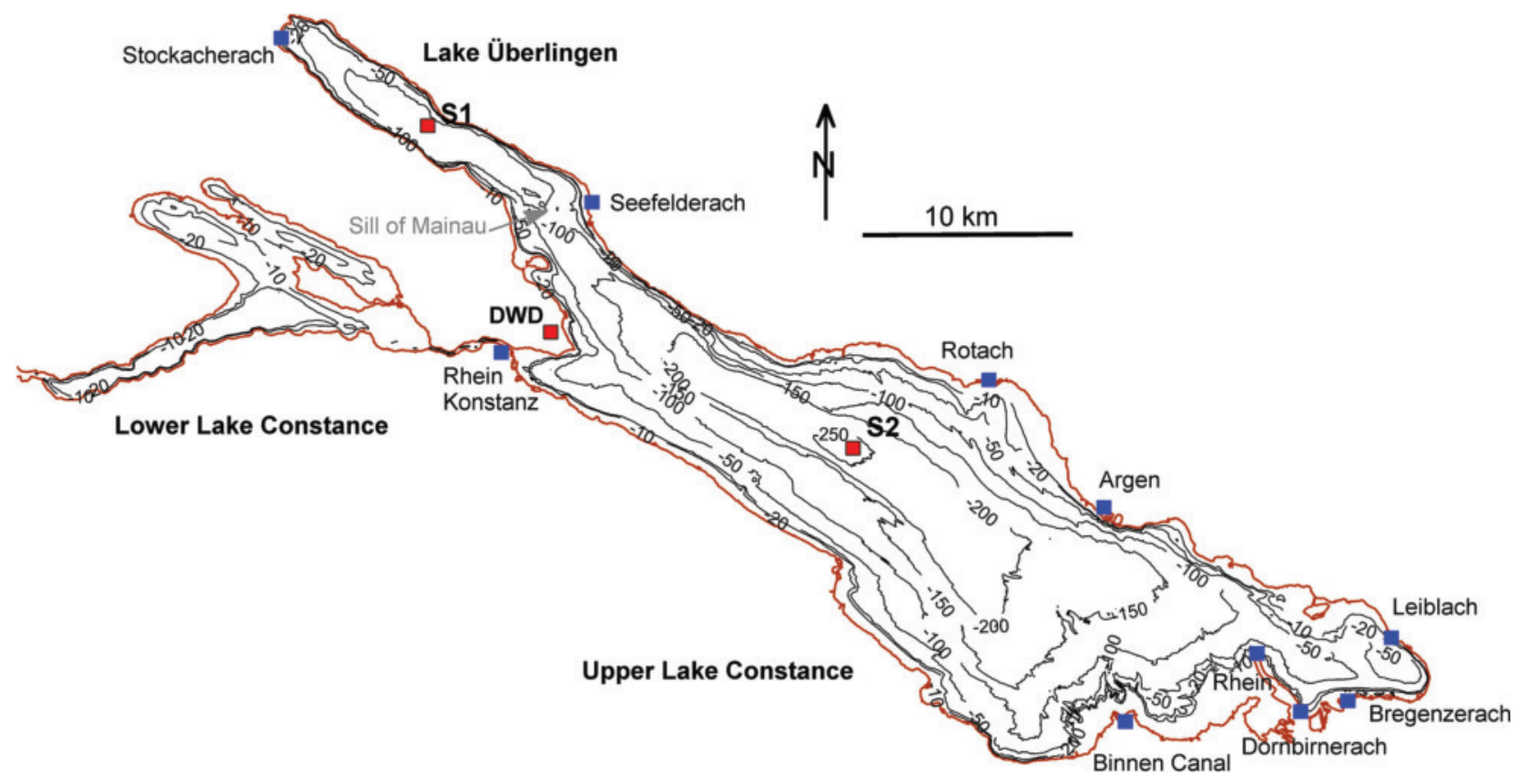

Figure 1. Main basins of Lake Constance: Upper Lake Constance with Lake Überlingen connected by the Sill of Mainau, and Lower Lake Constance. Contour lines indicate depth with reference to the elevation $394.5 \mathrm{~m}$ above mean sea level. Monitoring stations (red squares): S1: vertical temperature profiles, S2: vertical velocity profiles, and DWD (German Weather Service): meteorological data. Blue squares indicate the locations of significant river input considered in the model approaches. 
water temperature at a time interval of $60 \mathrm{~s}$ with an accuracy of $\pm 0.002{ }^{\circ} \mathrm{C}$. Between 30 July and 4 August 2009, a 614 kHz Acoustic Doppler Current Profiler (ADCP; Teledyne RD-Instruments, Poway, CA, USA) measured the current field of the upper $50 \mathrm{~m}$ of the water column at S2 (Fig. 1). The vertical bin resolution was $0.5 \mathrm{~m}$ and the sampling interval was $30 \mathrm{~s}$, averaging 20 pings per interval. Drifter experiments deployed 15 drifters in the main basin of Upper Lake Constance from 14 to 28 August 2009. The drifters consist of a cylindrical sail and a small surface buoy equipped with a data logger, GPS, and a GSM module (Peeters and Hofmann 2015). The data logger recorded position and time with a sampling interval of $5 \mathrm{~s}$. The sail of each drifter was constructed with a plastic tube and stabilised by 2 metal rings, one at the top and one at the bottom. Each sail had a diameter of $1 \mathrm{~m}$ and a height of $2 \mathrm{~m}$ and was attached to the surface buoy via a thin string ( $5 \mathrm{~m}$ length); therefore, the drifter was advected by the currents at $5 \mathrm{~m}$ depth.

Horizontally resolved dynamic wind fields used in this study were based on the outputs from the high-precision numerical weather prediction system of Consortium for Small-scale Modelling (COSMO), which is operationally simulated by the National Swiss Weather Service (Schättler 2009). COSMO is a nonhydrostatic limited-area model with a horizontal resolution of $2.2 \mathrm{~km}$ and temporal outputs of $1 \mathrm{~h}$. Continuously monitored hourly meteorological data (i.e., incident-solar radiation, relative humidity, cloud cover, and air temperature) were available from a station of the German Weather Service (DWD; Fig. 1) located next to the city of Konstanz. Time series data (15 min intervals) on discharge and temperature of the main tributaries to Upper Lake Constance (blue squares, Fig. 1) were provided by local authorities (Lake Research Institute, ISF-LUBW).

\section{D hydrodynamic models}

A brief description of the numerical implementation of ELCOM and Delft3D is provided to emphasise the similarities and the differences between the 2 models. The different formulations of the 2 models estimating the heat flux at the lake surface and the solar radiation absorbed into the water column are outlined in detail (Appendix A).

\section{ELCOM}

ELCOM is a free surface $z$-layer model that includes the simulation of temperature stratification and can be forced with horizontally resolved, dynamic wind fields (Hodges and Dallimore 2006). The fundamental numerical scheme of this model is from the TRIM approach
(Casulli and Cheng 1992). The grid stencil is the Arakawa C-grid; velocities are defined at cell faces while scalar concentrations are defined at cell centres. ELCOM uses the 3D mixed-layer approach to simulate the vertical turbulent fluxes in the momentum and the transport equations (Imberger and Patterson 1990, Hodges et al. 2000). This process allows increased computational efficiency and sharper gradients to be maintained with coarse grid resolution compared to the standard vertical turbulence equation using the vertical eddy viscosity (Rodi 1984). Discretisation of advection, baroclinic terms and horizontal diffusion is implemented as source terms in the fundamental, semi-implicit evolution of the velocity field (Hodges et al. 2000). For stratified flows, ELCOM uses an explicit discretization of the baroclinic terms in the momentum equation, imposing a timestep restriction based on the internal wave CourantFriedrichs-Lewy (CFL). The momentum input of wind is modelled using a stress boundary condition, evenly distributed over the surface wind-mixed layer (Imberger and Patterson 1990, Casulli and Cheng 1992). Heat exchange through the free-surface is estimated by the standard bulk transfer models (Imberger and Patterson 1981). ELCOM was simulated using the Boussinesq approximation, which neglects the nonhydrostatic pressure terms to estimate scalar transport (Hodges and Dallimore 2006).

\section{Delft3D}

Delft3D (Deltares 2014) was used to simulate thermal stratification and current field using the $z$-layer approach and the hydrostatic assumption. The same rectangular grid was applied as in ELCOM. Delft3D is based on a finite differencing approach with an ADI numerical scheme (Stelling 1984) and uses the same grid stencil used in ELCOM. Horizontal advection is estimated using a multi-directional upwind scheme (Stelling and Duinmeijer 2003). The turbulence closure model is based on the eddy-viscosity concept: the vertical exchange of horizontal momentum and mass is modelled through vertical eddy viscosity and eddy diffusivity coefficients. These coefficients are estimated from the $\mathrm{k}-\varepsilon$ model in which the turbulent kinetic energy $(\mathrm{k})$ and the dissipation rate of kinetic energy $(\varepsilon)$ are calculated by the transport equation (Uittenbogaard et al. 1992). The transport of scalars and heat is simulated by the advection-diffusion equation, as in ELCOM. Wind forcing is modelled by a stress boundary condition at the free surface, similar to the approach in ELCOM. However, wind stress is estimated using 3 wind speed ranges based on 3 wind-drag coefficients (Smith and Banke 1975). Note that the wind-drag coefficient of 
ELCOM is independent from wind speeds. The heat energy exchange at the free surface is estimated using the Murakami heat flux model (Murakami et al. 1985).

We summarize the main parameterization for both ELCOM and Delft3D setups as used in the simulations (Table 1) and provide a detailed description of the heat flux formulations (Appendix A).

\section{Model setup}

The ELCOM and Delft3D models for Upper Lake Constance were set up with the same horizontal and vertical discretisation using the rectilinear coordinates. Grid resolution in the horizontal was $200 \mathrm{~m}$. The vertical was discretized using 77 layers, the thickness of which increased from $0.7 \mathrm{~m}$ at the free surface up to $9.5 \mathrm{~m}$ at the lake bottom. The vertical resolution in the thermocline between 10 and $30 \mathrm{~m}$ water depth was $1 \mathrm{~m}$. The measured lake bed topography was linearly interpolated onto the horizontal grid cells to construct the model bathymetry. The time series of water inflow and temperature were imposed at the respective model nodes as point sources (blue squares, Fig. 1). Both models were forced by the horizontally resolved dynamic COSMO wind field (Schättler 2009). For the heat flux calculations, ELCOM used hourly time series of solar radiation, relative humidity, air temperature, and longwave radiation, whereas Delft3D used hourly time series of the externally calculated net-solar radiation, relative humidity, and air temperature from the meteorological station DWD (Fig. 1; formulations for the estimation of heat fluxes in ELCOM and Delft3D in Appendix A). Both modelling approaches were initialised with a vertical temperature profile from station S1 (Fig. 1) and a zero initial velocity field. The model simulations spanned a period of 6 weeks during the summer from 14 July to 31 August 2009; the first 2 weeks were required for the model spin-up and were not considered in the analysis of the model results.

\section{Statistical parameters}

Model performance was investigated by analysing the agreement between the simulated results and the measured data using a number of statistical parameters. The vertical profiles of the simulated temperatures were compared with the measured temperature profiles using the root-mean square error (RMSE). Simulated time series of the velocity components at different horizontal depth layers $(5,10$, and $15 \mathrm{~m})$ were also compared with those of the measured velocities using the RMSE. The periods of vertical oscillations of isotherms were

Table 1. Similarities and differences of the numerical schemes and the heat flux algorithms in ELCOM and Delft3D. $C_{d}=$ wind drag coefficient, $\mathrm{U}_{10}=$ wind velocity at $10 \mathrm{~m}$ height, TRIM = Tidal, Residual, Intertidal Mudflat, $A D I=$ alternating direction implicit. Heat flux equations are given in Appendix A.

\begin{tabular}{|c|c|c|c|}
\hline \multicolumn{2}{|l|}{ Parameter } & ELCOM & Delft3D \\
\hline Model grid & Horizontal & Rectilinear & Rectilinear \\
\hline & Vertical & $z$-layer & $z$-layer \\
\hline Wind stress $\left(C_{d}\right)$ & & 0.0013 & $\begin{array}{l}0.0019, \text { if } 0<\mathrm{U}_{10}<5 \mathrm{~m} \mathrm{~s}^{-1} \\
0.0019, \text { if } 5<\mathrm{U}_{10}<100 \mathrm{~m} \mathrm{~s}^{-1} \\
0.0723, \text { if } \mathrm{U}_{10}>100 \mathrm{~m} \mathrm{~s}^{-1}\end{array}$ \\
\hline Numerical scheme & & TRIM & $\mathrm{ADI}$ \\
\hline Numerical method & & Finite-difference/-volume & Finite-difference \\
\hline Time step limitation & & CFL criterion & CFL criterion \\
\hline Grid stencil & & Arakawa C-grid & Arakawa C-grid \\
\hline Facilitating free-surface change & & Flooding-drying scheme & Flooding-drying scheme \\
\hline \multirow[t]{2}{*}{$\begin{array}{l}\text { Pressure distribution along the } \\
\text { vertical }\end{array}$} & $\begin{array}{l}\text { Hydrodynamic } \\
\text { pressure }\end{array}$ & neglected & neglected \\
\hline & Hydrostatic solution & Yes & Yes \\
\hline Vertical mixing & & 3D mixed-layer & $\mathrm{k}-\varepsilon$ model \\
\hline \multirow[t]{3}{*}{ Advection-diffusion schemes } & $\begin{array}{r}\text { Advection for } \\
\text { momentum }\end{array}$ & Semi-implicit & Multi-directional-upwind \\
\hline & $\begin{array}{l}\text { Advection for } \\
\text { transport }\end{array}$ & Semi-implicit & Van Leer-2 (Van Leer 1974) \\
\hline & Horizontal diffusion & Constant: $0.1 \mathrm{~m}^{2} \mathrm{~s}^{-1}$ & $\begin{array}{l}\text { Ambient values: } \\
\text { Eddy-viscosity } 0.1 \mathrm{~m}^{2} \mathrm{~s}^{-1} \\
\text { Eddy-diffusivity } 1.0 \mathrm{~m}^{2} \mathrm{~s}^{-1}\end{array}$ \\
\hline \multirow{4}{*}{$\begin{array}{l}\text { Total heat energy transfer at free- } \\
\text { surface }\left(\mathrm{H}_{\text {tot }}\right)=\mathrm{H}_{\mathrm{s}}+\left(\mathrm{H}_{\mathrm{A}^{-}}-\mathrm{H}_{\mathrm{w}}\right)-\mathrm{H}_{\mathrm{E}^{-}} \\
\mathrm{H}_{\mathrm{C}}\end{array}$} & Net solar radiation $\left(\mathrm{H}_{\mathrm{s}}\right)$ & $\begin{array}{l}\text { Incident solar radiation provided as input, internally } \\
\text { calculate net radiation (eq. } \mathrm{A} 2 \text { ) }\end{array}$ & $\begin{array}{l}\text { Externally calculated using Ollinger } \\
\text { (1999) and provided as input (eq. A5) }\end{array}$ \\
\hline & $\begin{array}{l}\text { Net long-wave } \\
\text { radiation }\left(\mathrm{H}_{\mathrm{A}}-\mathrm{H}_{\mathrm{w}}\right)\end{array}$ & $\begin{array}{l}\text { Externally calculated long-wave radiation (Iziomon et al. } \\
2003 \text { ) as input, internally calculate net long-wave } \\
\text { radiation (eq. A10) }\end{array}$ & $\begin{array}{l}\text { Berliand's formula (Murakami et al. } \\
\text { 1985) (eq. A11) }\end{array}$ \\
\hline & Latent heat flux $\left(\mathrm{H}_{\mathrm{E}}\right)$ & $\begin{array}{l}\text { Estimates using the Bulk formula in Fischer et al. (1979) } \\
\text { (eq. A13) }\end{array}$ & $\begin{array}{l}\text { Dalton's law of mass transfer } \\
\text { (Murakami et al. 1985) (eq. A16) }\end{array}$ \\
\hline & Sensible heat flux $\left(\mathrm{H}_{\mathrm{C}}\right)$ & $\begin{array}{l}\text { Estimates using the Bulk formula in Fischer et al. (1979) } \\
\text { (eq. A20) }\end{array}$ & $\begin{array}{l}\text { Estimates based on latent heat flux } \\
\text { using Bowen's ratio (Deltares 2014) } \\
\text { (eq. A21) }\end{array}$ \\
\hline
\end{tabular}


estimated by analysing the power spectral density (PSD) of 2 isotherms, 10 and $15{ }^{\circ} \mathrm{C}$. Autocovariance function (ACF) was used to identify the wave period, crosscovariance function (CCF) was used to estimate the agreement of the phase between the measured and the simulated velocities, and band-pass filters were used to identify the periods of the oscillatory patterns of isotherms and velocity components. Surface velocity magnitudes from the drifter experiments and the simulations were compared using the coefficient of determination $\left(R^{2}\right)$ and the RMSE. Normalised difference (D) between the simulated surface velocity components was estimated to qualitatively compare the surface velocity distributions of the models.

\section{Root mean square error (RMSE)}

The RMSE indicates the standard deviation between the measured and the simulated values as:

$$
\operatorname{RMSE}=\left[\frac{1}{\mathrm{n}} \sum_{\mathrm{i}=1}^{n}\left(\mathrm{P}_{\mathrm{i}}-\mathrm{M}_{\mathrm{i}}\right)^{2}\right]^{1 / 2},
$$

where $\mathrm{P}$ is the model-simulated value, $\mathrm{M}$ is the measured value, and $\mathrm{n}$ is the number of samples. The lower the RMSE the better the agreement between model results and data. Note, however, that the RMSE can become large if model and data are both characterised by periodic signals with large amplitudes and the same period but shifted in phase. Hence, model results and data may indicate almost identical periods and amplitudes of internal waves, but the RMSE values may be large because of a phase shift between simulated and measured waves.

\section{Coefficient of determination $\left(\mathrm{R}^{2}\right)$ and linear regression}

$R^{2}$ is defined as the squared value of the coefficient of correlation (Krause et al. 2005) and quantifies the fraction of the variance in the measured data explained by the simulated results:

$$
R^{2}=\left(\frac{\sum_{\mathrm{i}=1}^{\mathrm{n}}\left(\mathrm{M}_{\mathrm{i}}-\overline{\mathrm{M}}\right)\left(\mathrm{P}_{\mathrm{i}}-\overline{\mathrm{P}}\right)}{\sqrt{\sum_{\mathrm{i}=1}^{\mathrm{n}}\left(\mathrm{M}_{\mathrm{i}}-\overline{\mathrm{M}}\right)^{2}} \sqrt{\sum_{\mathrm{i}=1}^{\mathrm{n}}\left(\mathrm{P}_{\mathrm{i}}-\overline{\mathrm{P}}\right)^{2}}}\right)^{2},
$$

where $\overline{\mathrm{P}}$ is the averaged model-simulated value and $\overline{\mathrm{M}}$ is the averaged measured value.

A value of 0 indicates that the model does not explain the variance in the data, and a value of 1 indicates that the variance of data is fully explained by the model results. Linear regression of model results versus data not only provides $R^{2}$ but also the gradient and the intercept of the regression line. These properties can be used as additional criteria to judge model performance whereby good model performance is indicated by a gradient close to 1 and an intercept close to 0 .

\section{Power spectral density (PSD)}

PSD was calculated using the Welch method with a Hamming filter and half-overlapping windows (Gómez-Giraldo et al. 2006). To identify the period of internal waves, the spectra of isotherms were calculated based on $30 \mathrm{~d}$ of data with a temporal resolution of $10 \mathrm{~min}$. Several window sizes were applied $(13 \mathrm{~d}, 6 \mathrm{~d}, 3$ $\mathrm{d}$, and $12 \mathrm{~h}$ ), allowing a reduction of confidence intervals at high frequencies and a better frequency resolution at low frequencies. Peaks in the power spectrum indicate at which frequencies (or periods) the variance in the time series is particularly high.

\section{Autocovariance function (ACF) and cross- covariance function (CCF)}

ACF indicates the correlation coefficient of a time series as a function of time lag and was used to identify periodic patterns. An average period of the internal waves was estimated by considering the occurrence of crests and troughs throughout the evaluation period. Note that this procedure assumes the presence of a coherent wave pattern during the entire time period included in the assessment. Wave amplitude was estimated as the average crest-to-trough value. CCF provides the correlation coefficient between 2 time series as a function of time lag, useful for identifying agreements of the periodic patterns and the phase shift between oscillations in 2 time series. The phase shift of the waves between the models and the data and between the models was identified by the time lag in CCF. The reliability of ACF and CCF approaches was analysed by estimating the confidence intervals.

\section{Low- and band-pass filters}

Isotherms and time series of velocity components were analysed using band-pass filters to identify the period and amplitude of the internal waves. Two isotherms, 10 and $15^{\circ} \mathrm{C}$, spanning a period of $30 \mathrm{~d}$, were filtered setting the lower and the upper limits as 60 and $200 \mathrm{~h}$, respectively, to analyse the Kelvin-type waves (Appt et al. 2004). The Poincaré-type waves were investigated by filtering the time series ( $4 \mathrm{~d}$ length) of the east and the north velocity components at 5 and $15 \mathrm{~m}$ water depth using the lower and upper filter limits of 7 and $15 \mathrm{~h}$ (Appt et al. 2004). In both analyses, average wave periods were estimated by considering the time period 
and the number of crests and troughs, similar to the analysis in ACF. Average amplitudes were obtained by calculating the distance from crests to troughs over the time period.

The $5 \mathrm{~s}$ interval coordinate data of the drifters was analysed by applying a low-pass filter to estimate the drifter velocities. The coordinate data were first lowpass filtered using a Butterworth filter with a $5 \mathrm{~min}$ lower limit of the pass band. Velocities (velocity components and magnitude) were then determined from the filtered data using the temporal change of the position within $5 \mathrm{~s}$ and subsampling them over $30 \mathrm{~min}$ intervals ( $30 \times 60 / 5=360$ velocity values).

\section{Normalised velocity difference and directional difference within velocity-range classes}

Direction and magnitude of the simulated horizontal velocity and the drifter data were stacked into velocity classes with a class interval of $0.025 \mathrm{~m} \mathrm{~s}^{-1}$ from 0 to $0.250 \mathrm{~m} \mathrm{~s}^{-1}$ based on the drifter velocity magnitude. Directional differences of the simulated and the drifter velocities of these classes were estimated considering the difference of velocity orientations. Normalised velocity difference was calculated by dividing the difference of the simulated and the drifter velocity magnitudes by the mean value of the respective velocity class.

\section{Normalised difference (D)}

Normalised difference (D) between the model-simulated horizontal velocity components within the model domain was estimated using the following definition, similar to the approach of the normalised Fourier norm in Huang et al. (2010a):

$$
\mathrm{D}(\mathrm{t})=\sqrt{\frac{\sum_{\mathrm{t}=1}^{\mathrm{n}}\left[\left(\mathrm{u}_{\mathrm{e}}^{\mathrm{t}}-\mathrm{u}_{\mathrm{d}}^{\mathrm{t}}\right)^{2}+\left(\mathrm{v}_{\mathrm{e}}^{\mathrm{t}}-\mathrm{v}_{\mathrm{d}}^{\mathrm{t}}\right)^{2}\right]}{\sum_{\mathrm{t}=1}^{\mathrm{n}}\left[\left(\mathrm{u}_{\mathrm{d}}^{\mathrm{t}}\right)^{2}+\left(\mathrm{v}_{\mathrm{d}}^{\mathrm{t}}\right)^{2}\right]}},
$$

where $\mathrm{u}$ and $\mathrm{v}$ are the east and north velocity components at $5 \mathrm{~m}$ water depth within the model domain (note that the drifters were deployed at $5 \mathrm{~m}$ water depth), subscripts e and d indicate ELCOM and Delft3D, and $t$ indicates the time point of the respective drifter experiment. The lower the $\mathrm{D}$ the higher the agreement between the ELCOM and the Delft3D simulated velocity fields.

\section{Results}

Model simulation results on the temperature distributions and the velocity fields in Upper Lake Constance were compared with the measured data and between the two 3D models ELCOM and Delft3D. First, the heat flux components and the total heat flux at the water surface of the location S1 (Fig. 1) were compared between the 2 models. Next, the simulated time series of vertical temperature profiles at station S1 and the vertical structure of velocity profiles at station S2 (Fig. 1) were compared with those of the measured profiles. Finally, the magnitudes of current velocities and the horizontal circulation patterns were compared between the simulated velocities and the velocities estimated from the drifter experiments in the main basin of Upper Lake Constance.

\section{Heat fluxes in Lake Überlingen}

The different empirical models used to describe the heat flux components implemented in ELCOM and Delft3D (Appendix A) were compared by applying the respective empirical relations using meteorological data and measured surface water temperatures from 14 July to 31 August 2009 (Fig. 2). Net shortwave radiation was essentially the same in both models (Fig. 2a). In both models, net longwave radiation had a similar pattern of variation (i.e., similar periodicity and phase), whereas in ELCOM the amplitude of the variation was somewhat larger than in Delft3D (Fig. 2b). In both models, the latent heat flux was negative, indicating a loss of heat from the lake surface. The temporal variability in the latent heat flux was similar in both models (Fig. 2c). The magnitude of the latent heat fluxes was slightly higher in ELCOM than in Delft3D. By contrast, the sensible heat fluxes in ELCOM were smaller than those in Delft3D (Fig. 2d); however, phasing of both models more closely agreed. The estimated total heat flux at the water surface (Fig. 2e) showed that the difference in the total heat fluxes into the lake was marginal between ELCOM and Delft3D.

\section{Temporal variation of the thermal structure in the basin Lake Überlingen}

Model-simulated temperature stratification from 1 to 31 August 2009 (Fig. 3) was compared to the measured time series of vertical temperature profiles at location S1 (Lake Überlingen). Simulated and measured temperatures showed that the lake warmed in the upper mixed layer of the water column during the last 2 weeks of the evaluation period. The stratified thermal structure of the lake is modulated by different periodic oscillations, which are initially generated by wind forcing on the lake surface. Visual comparison indicates that both ELCOM and Delft3D were able to reasonably capture the vertical distribution of temperatures found in the measured data. 


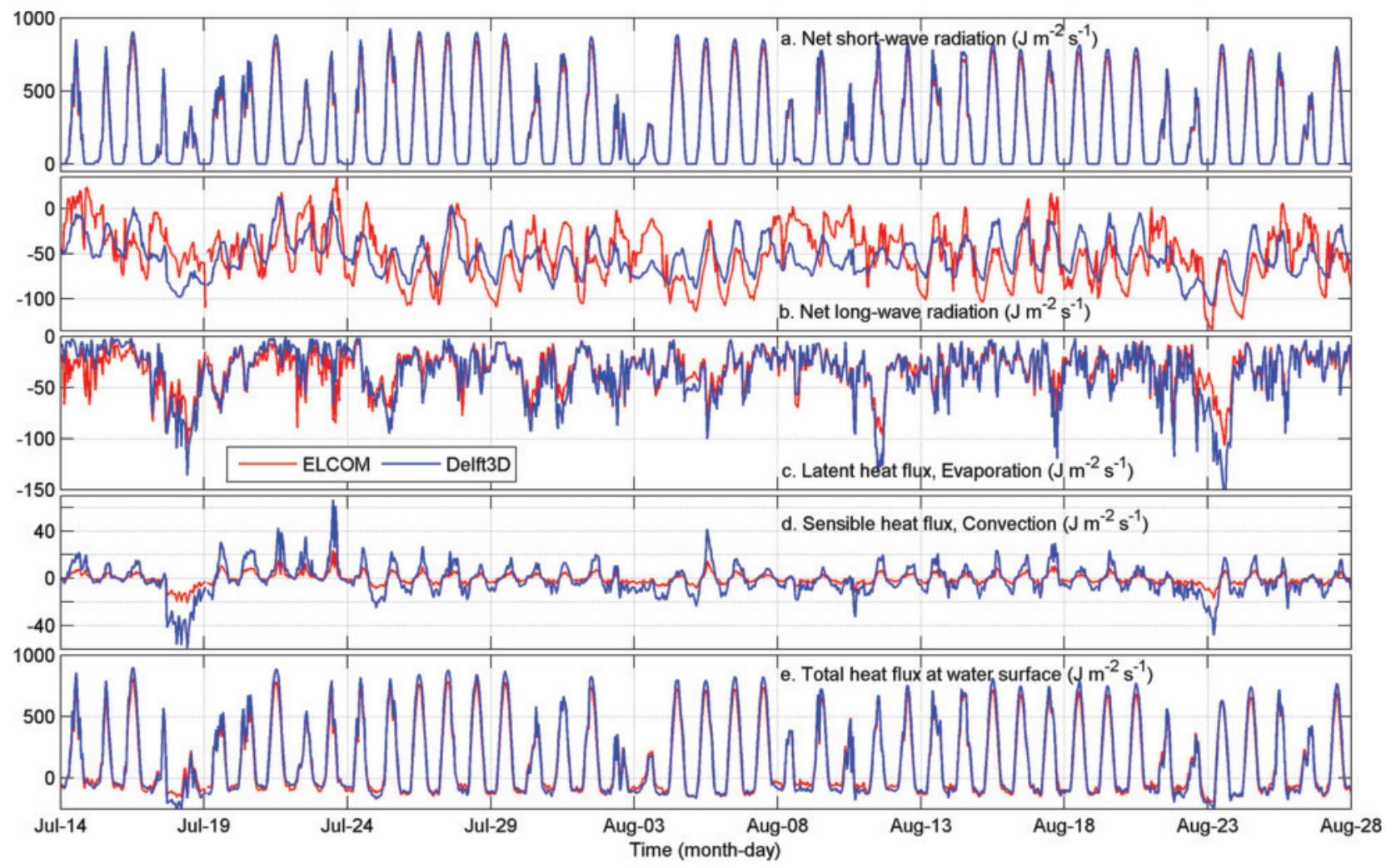

Figure 2. Estimated heat flux components and the total heat flux at the water surface of the location S1 in Lake Überlingen (Fig. 1) for ELCOM (red line) and Delft3D (blue line) using the field data and the empirical relations of each model: (a) net short-wave radiation, (b) net long-wave radiation, (c) latent heat flux, (d) sensible heat flux, and (e) total heat flux at water surface.

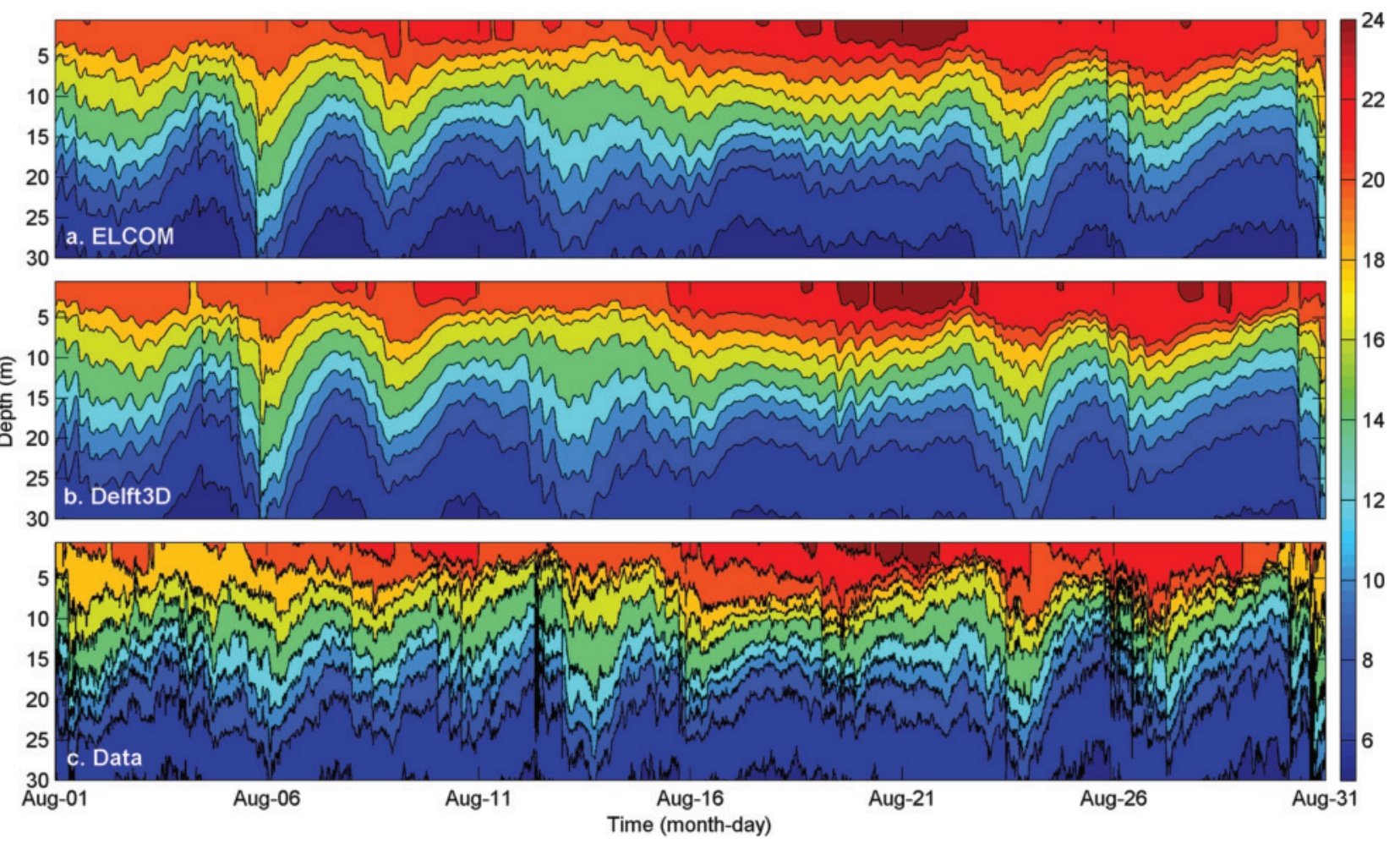

Figure 3. Model-simulated (a) ELCOM, (b) Delft3D, and (c) measured data for water temperature $\left({ }^{\circ} \mathrm{C}\right)$ showing stratification and internal wave structure at S1 (Fig. 1). For clarity, only the depth range between 0 and $30 \mathrm{~m}$ is shown. Temperature scale is on right-hand side. 
The stratified thermal structure indicates major oscillations of isotherms (internal waves). By counting the peak-to-peak distance, these oscillations seem to have a period of $\sim 3.5 \mathrm{~d}$. Both model-simulated wave patterns agree fairly well with the data with respect to the amplitudes and periods of the major oscillation. Additionally, minor oscillations with higher frequencies exist in both the simulated results and the data. In the data, high frequency internal waves were captured (e.g., on 12 and 26 Aug). However, these high frequency waves were not found in the simulated results of either of the models (horizontal model grid $\sim 200 \mathrm{~m}$ ). Note that the simulated wave structure in terms of the major oscillations of isotherms was fairly similar in both ELCOM and Delft3D.

In the example of the 15 and $10{ }^{\circ} \mathrm{C}$ isotherms, the major oscillatory pattern (period, amplitude, and phase) of the internal waves generally agreed between the model results and the measured data (Fig. 4a-b). However, in the first 2 weeks of the evaluation period (1-16 Aug) the amplitudes of the oscillations of the simulated isotherms were larger than those of the measured isotherms. In addition, the oscillations were phaseshifted between the model results and the data. In the last 2 weeks, the oscillations of isotherms simulated with the models were generally in phase with the oscillations in the data, whereas the amplitudes of the oscillations simulated were slightly lower than those observed. For the $10{ }^{\circ} \mathrm{C}$ isotherm, the highest RMSE of $1.91 \mathrm{~m}$ was found for Delft3D but was $1.80 \mathrm{~m}$ for ELCOM. These values were lower for the $15{ }^{\circ} \mathrm{C}$ isotherm (i.e., 1.36 and $1.57 \mathrm{~m}$, respectively). The RMSE values based on the deviation between the isotherm depths simulated with ELCOM and Delft3D were 0.74 and $1.02 \mathrm{~m}$ for the 10 and $15{ }^{\circ} \mathrm{C}$ isotherm, respectively, indicating that the agreement of the simulated stratification and of the isotherm depths between the models was higher than between the models and the data.

The PSD estimated for the simulated and the measured isotherm depths (Fig. 4c-d) showed a prominent peak in the measured and the simulated isotherm depths at $84 \mathrm{~h}\left(3.30 \times 10^{-6} \mathrm{~Hz}\right)$ at both the 10 and $15{ }^{\circ} \mathrm{C}$ isotherms. The period estimated from the crest and trough counting of the band-pass-filtered isotherms is $82 \mathrm{~h}$ for the measured isotherm depths and $86 \mathrm{~h}$ for the isotherm depths simulated with ELCOM and Delft3D. Furthermore, the PSD of the measured isotherm depths indicated a second peak at $14 \mathrm{~h}\left(1.96 \times 10^{-5} \mathrm{~Hz}\right)$ for both isotherms. A similar second peak was also observed in the simulated results with both models, with the period slightly shifted toward $11 \mathrm{~h}\left(2.56 \times 10^{-5} \mathrm{~Hz}\right)$. The prominent peak in the PSD at $84 \mathrm{~h}$ represents a Kelvin-type wave while the other at $14 \mathrm{~h}$ indicates a Poincaré-type wave.

The vertical temperature profiles at station S1 were averaged over the evaluation period from 1 to 31 August
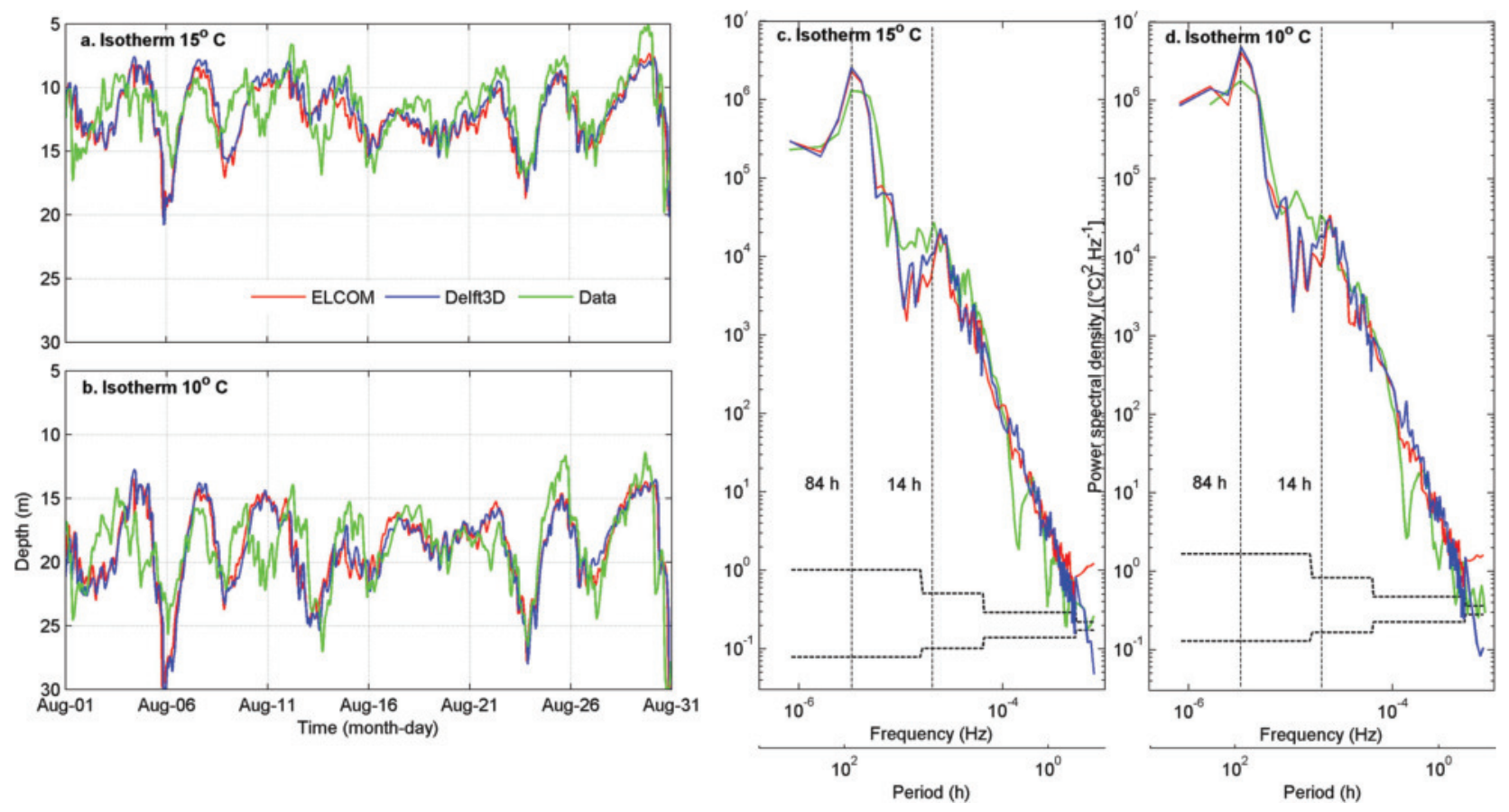

Figure 4. Temporal course and power spectral density (PSD) of the (a and c) $15^{\circ} \mathrm{C}$ and (b and d) $10{ }^{\circ} \mathrm{C}$ isotherms at location $\mathrm{S} 1$ (Fig. 1 ) from 1 to 31 August 2009. Colour coding: ELCOM: red line, Delft3D: blue line, and data: green line. 


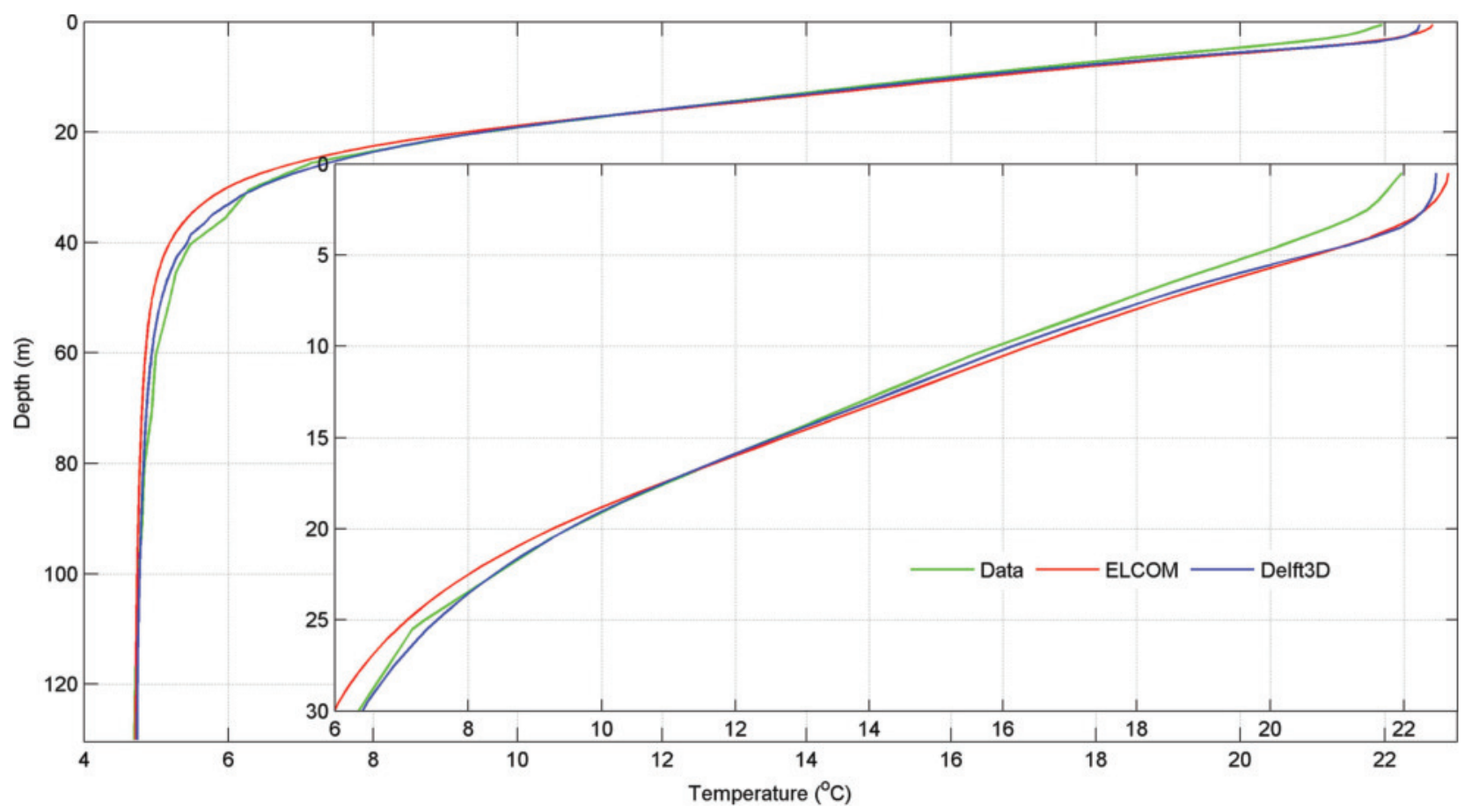

Figure 5. Averaged measured and simulated vertical temperature profiles at S1 (Fig. 1) between 1 and 31 August 2009 (data: green line, ELCOM: red line, Delft3D: blue line). Inset shows the upper $30 \mathrm{~m}$.

for the data and the simulation results with both models (Fig. 5). In the upper $5 \mathrm{~m}$ of the water column, both model simulations were on average $0.5-1{ }^{\circ} \mathrm{C}$ higher than the measured temperatures during the evaluation period. The simulated vertical temperature distribution in the top $20 \mathrm{~m}$ was similar between models (Fig. 5), and the average water temperatures closely agreed $\left(\mathrm{RMSE}_{\mathrm{ELCOM}, \mathrm{Delft3D}}=0.16^{\circ} \mathrm{C}\right)$. Between 20 and $30 \mathrm{~m}$, the average temperatures simulated with ELCOM were slightly lower than those observed and simulated with Delft3D. The maximum temperature difference between the models was $\sim 0.5^{\circ} \mathrm{C}$ at $30 \mathrm{~m}$ depth, whereas the temperature difference at the surface was only $0.2{ }^{\circ} \mathrm{C}$. The average temperature profile simulated with Delft3D showed a marginally higher agreement with the data than that of ELCOM (i.e., $0-30 \mathrm{~m}$, $\mathrm{RMSE}_{\mathrm{ELCOM}}=0.58$ ${ }^{\circ} \mathrm{C}$, RMSE $\mathrm{Delft3D}_{\mathrm{D}}=0.49^{\circ} \mathrm{C}$ ).

The temporal course of the model-simulated vertical temperature profiles $(0-30 \mathrm{~m}$ water depth) at $\mathrm{S} 1$ (Fig. 1) was statistically compared to the measured profiles using the RMSE. The RMSE values ranged between 0 and $4{ }^{\circ} \mathrm{C}$ in both models and showed oscillatory patterns (Fig. 6). In the first 2 weeks, the oscillatory pattern of the models was more pronounced (i.e., range of variation) than in the last 2 weeks. The averaged RMSE value from the simulated results of ELCOM was

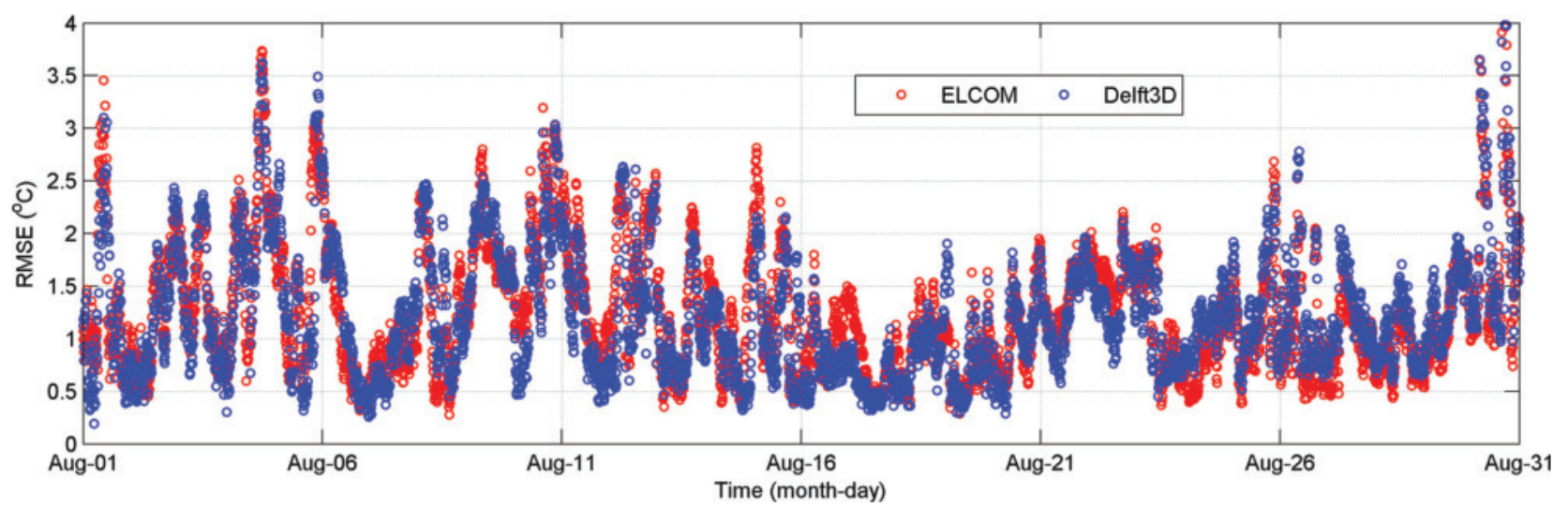

Figure 6. RMSE between the measured and the simulated vertical temperature profiles at S1 (Fig. 1) from 1 to 31 August 2009. 
essentially the same as that from Delft3D (i.e., 1.25 and $1.22{ }^{\circ} \mathrm{C}$, respectively).

\section{Vertical velocity structure in the central basin of Upper Lake Constance}

The horizontal velocity components (i.e., east and north) and the velocity vectors in the simulated and the measured velocities at location S2 (Fig. 7) exemplify water depths 5, 10, and $15 \mathrm{~m}$ between 30 July and 2 August 2009. At $5 \mathrm{~m}$ water depth (Fig. $7 \mathrm{a}, \mathrm{d}$ ), the temporal variation of the measured velocity in both components showed more irregular oscillation than at 10 and $15 \mathrm{~m}$ water depth. Furthermore, the agreement of the oscillatory pattern between the measured and the simulated velocities was low compared to 10 and $15 \mathrm{~m}$ water depth. The greatest difference between the data and the simulated velocities occurred at $0600 \mathrm{~h}$ on 30 July for the east component (data: $0.08 \mathrm{~m} \mathrm{~s}^{-1}$; ELCOM: $-0.08 \mathrm{~m} \mathrm{~s}^{-1}$; and Delft3D: $-0.05 \mathrm{~m} \mathrm{~s}^{-1}$ ) and at $1000 \mathrm{~h}$ on 30 July for the north component (data: $-0.17 \mathrm{~m} \mathrm{~s}^{-1}$; ELCOM: $0 \mathrm{~m} \mathrm{~s}^{-1}$; and Delft3D: $-0.03 \mathrm{~m} \mathrm{~s}^{-1}$ ). However, during the other days ( $31 \mathrm{Jul}$ to $2 \mathrm{Aug}$ ), the oscillatory pattern of both velocity components in ELCOM and Delft3D generally had lower discrepancies from the oscillatory pattern of the data (Fig. 7a). However, differences between the 2 models were smaller than between the models and the data. At some time points, the model-simulated velocity vectors at $5 \mathrm{~m}$ water depth had strong differences, or even pointed in the opposite direction compared to the data. In fact, no such discrepancies were found between the model-simulated velocity vectors, which agreed during most of the time points. At $10 \mathrm{~m}$ water depth for both velocity components (Fig. 7b, e), the measured data showed a more distinct oscillatory pattern than at $5 \mathrm{~m}$ water depth. The east and north components were about $90^{\circ}$ phase-shifted to each other. The simulated velocities in both components of ELCOM were slightly higher than the data while the Delft3D velocities were slightly lower. The agreement between the simulated and the measured velocity vectors was better at the $10 \mathrm{~m}$ water depth than at $5 \mathrm{~m}$ depth (Fig. 7e). For example, at the $10 \mathrm{~m}$ depth, the simulated and the measured velocity vectors never pointed in opposite directions. At $15 \mathrm{~m}$ water depth, the oscillatory pattern and the agreement between the modelled and the
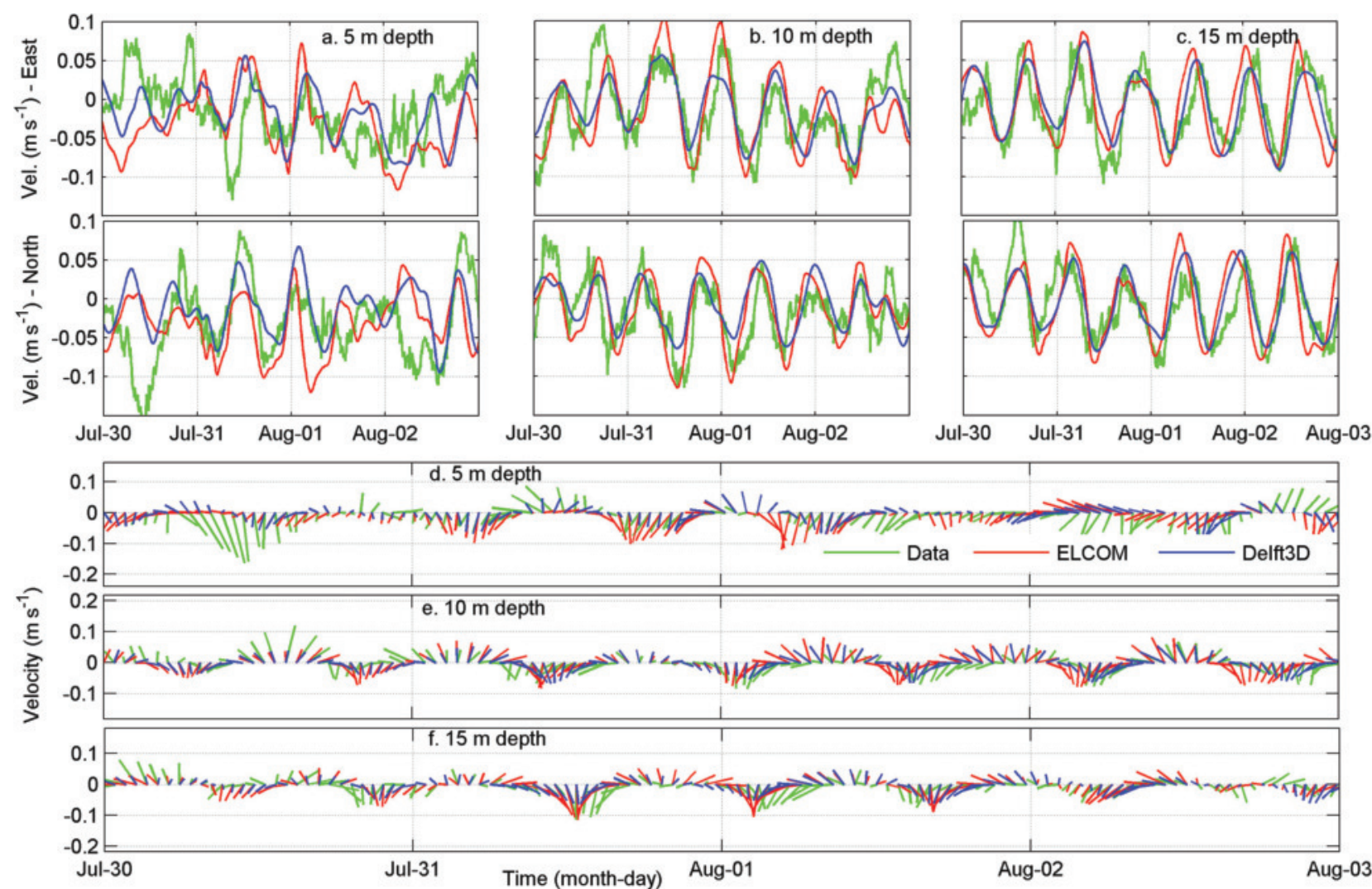

Figure 7. Horizontal velocity components and velocity vectors at 3 water depths in the central basin of Upper Lake Constance measured and simulated from 30 July to 2 August 2009. Velocity components: (a) east and north at $5 \mathrm{~m}$, (b) $10 \mathrm{~m}$, and (c) $15 \mathrm{~m}$ water depth. Corresponding velocity vectors at (d) $5 \mathrm{~m}$, (e) $10 \mathrm{~m}$, and (f) $15 \mathrm{~m}$ water depth. Colour coding: data: green; ELCOM: red; and Delft3D: blue. 
Table 2. RMSE values $\left(\mathrm{m} \mathrm{s}^{-1}\right)$ for the east and north velocity components at 5,10 , and $15 \mathrm{~m}$ water depths of the mooring location S2 (Fig. 1).

\begin{tabular}{|c|c|c|c|c|c|c|}
\hline \multirow[b]{2}{*}{ Water depth (m) } & \multicolumn{2}{|c|}{ ELCOM - Data } & \multicolumn{2}{|c|}{ Delft3D - Data } & \multicolumn{2}{|c|}{$\begin{array}{l}\text { ELCOM - } \\
\text { Delft3D }\end{array}$} \\
\hline & East & North & East & North & East & North \\
\hline 5 & 0.058 & 0.056 & 0.047 & 0.051 & 0.030 & 0.033 \\
\hline 10 & 0.039 & 0.042 & 0.036 & 0.042 & 0.026 & 0.028 \\
\hline 15 & 0.040 & 0.042 & 0.031 & 0.030 & 0.030 & 0.031 \\
\hline
\end{tabular}

simulated velocity components was similar to that at the $10 \mathrm{~m}$ water depth (Fig. 7c, f).

The agreement between the simulated and the measured velocities was statistically analysed by estimating the RMSE values for the velocity components at 5, 10, and $15 \mathrm{~m}$ water depths between 30 July and 2 August (Table 2). At all depth levels, the RMSE of the ELCOM-simulated velocity components (i.e., east and north) exceeded the respective values of Delft3D. The maximum difference of the velocities between the models and the data occurred for the east velocity of ELCOM at $5 \mathrm{~m}$ water depth $\left(\mathrm{RMSE}=0.058 \mathrm{~m} \mathrm{~s}^{-1}\right.$ ) because of the predicted irregular oscillatory pattern. However, the difference in the RMSE between ELCOM and Delft3D was only $0.011 \mathrm{~m} \mathrm{~s}^{-1}$ (i.e., RMSE of ELCOM was on average $\sim 20 \%$ higher than Delft3D). The closer agreement between the models than between the models and the data was reflected by the lowest RMSE values between ELCOM and Delft3D at all depth levels for both velocity components.

The east velocity component at $15 \mathrm{~m}$ water depth was further statistically analysed using the ACF and the CCF to compare the agreement between the measured and the simulated periodic pattern of the velocities. The normalised ACFs and confidence intervals (CI) were determined for the data (green line), ELCOM (red line), and Delft3D (blue line; Fig. 8a), and the normalised CCFs were determined for the data-ELCOM (green line),
data-Delft3D (red line), and ELCOM-Delft3D (blue line; Fig. 8b).

The estimated ACF curves for the measured and the simulated velocities indicated a dominant oscillation with a period of $14 \mathrm{~h}$ (oscillation between -10 and $10 \mathrm{~h}$ lags in Fig. 8a), characterising a Poincaré-type wave pattern. Application of the band-pass filter on these velocities also resulted in a periodic signal with a $14 \mathrm{~h}$ period for both measured data and model results. As the time lag increased, the east components of the velocities simulated with both models lagged behind the data, with the lag of ELCOM simulations marginally higher than that of the Delft3D simulation. A decrease in the ACF value in the measured velocities increased with the time lag compared with that of the simulated results. By contrast, both ELCOM and Delft3D showed a slight decrease in ACF with increasing time lag while the variation of ACF in the model results was fairly similar. CCF curves between the measured and the simulated velocities were consistent with the $14 \mathrm{~h}$ periodicity of the velocity oscillations (Fig. $8 b)$. In ACF, the CI was similar for both model results (0.068) and marginally lower for the data (0.049). The lowest CI of CCF was obtained between the data and Delft3D (0.044), but it was only slightly higher (0.047) between the data and ELCOM. The analysis indicates that ELCOM and Delft3D captured similar oscillatory patterns.

Results of the band-pass filter analyses for the 2 wave patterns were summarized (Table 3 ) with the estimated phase lags from the CCF analysis. The amplitude of the isotherm oscillations connected to the Kelvin-type wave was larger at lower layers $\left(2.6 \mathrm{~m}\right.$ at $10^{\circ} \mathrm{C}$ isotherm) than closer to the surface $\left(2.0 \mathrm{~m}\right.$ at $15^{\circ} \mathrm{C}$ isotherm). This observation was also captured by the simulations with both models, although the simulated isotherm oscillations have slightly higher amplitudes than those measured. The amplitudes of the oscillations of isotherm simulated with ELCOM and Delft3D were essentially the same.
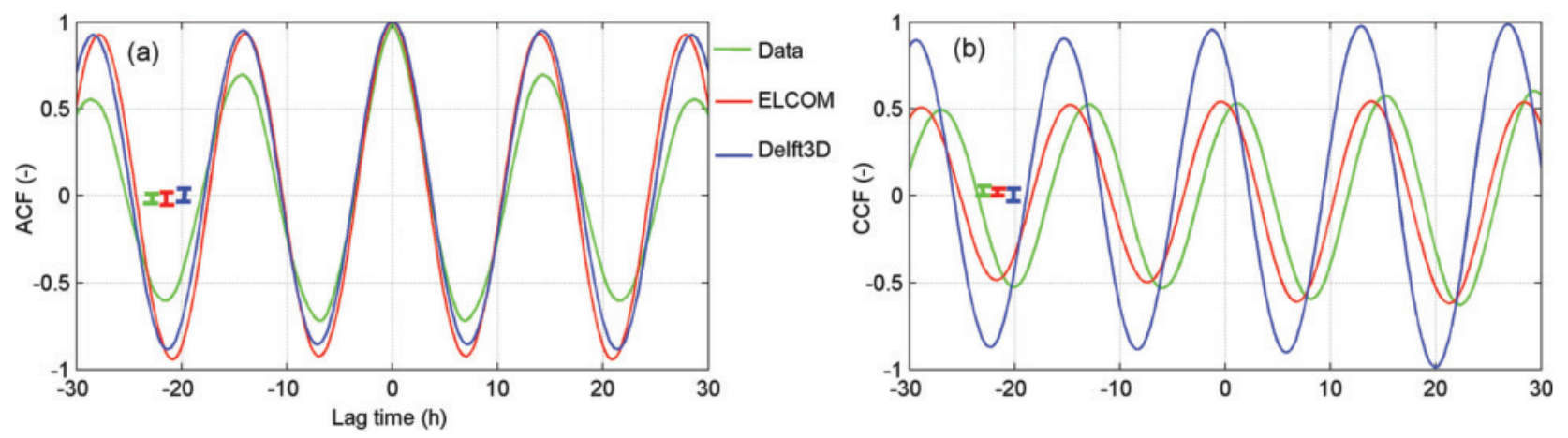

Figure 8. (a) Autocovariance function (ACF; data: green line; ELCOM: red line; Delft3D: blue line) and (b) cross-covariance function (CCF; data-ELCOM: green line; data-Delft3D: red line; ELCOM-Delft3D: blue line) with confidence intervals (vertical bars) of the east velocity component at $15 \mathrm{~m}$ depth at station S1 (Fig. 1). 
Table 3. Estimated periods and amplitudes and of the isotherm oscillations in Lake Überlingen associated with the basin-scale Kelvintype wave in Lake Constance and of the east and north velocity components at 5 and $15 \mathrm{~m}$ water depths associated with the Poincarétype waves in the central basin of Lake Constance. The analysis is based on band-pass-filtered isotherm depths and velocity components. Phase lags between data and simulation results are determined based on CCF applied to the data and the simulation results.

\begin{tabular}{|c|c|c|c|c|c|c|}
\hline \multirow[b]{2}{*}{ Wave type } & & \multirow[b]{2}{*}{ Parameter } & & \multirow[b]{2}{*}{ Data } & \multicolumn{2}{|c|}{ Model results } \\
\hline & & & & & ELCOM & Delft3D \\
\hline \multirow[t]{6}{*}{ Kelvin } & Isotherm $15^{\circ} \mathrm{C}$ & Period (h) & & 82 & 86 & 86 \\
\hline & & Amplitude (m) & & 2.0 & 2.2 & 2.3 \\
\hline & & Phase lag (h) & & - & -0.5 & -0.5 \\
\hline & Isotherm $10^{\circ} \mathrm{C}$ & Period (h) & & 82 & 86 & 86 \\
\hline & & Amplitude (m) & & 2.6 & 3.0 & 3.1 \\
\hline & & Phase lag (h) & & - & -1.5 & -0.5 \\
\hline \multirow[t]{14}{*}{ Poincaré } & $5 \mathrm{~m}$ water depth & Period (h) & East & 10 & 14 & 11 \\
\hline & & & North & 10 & 14 & 11 \\
\hline & & Amplitude $\left(\mathrm{m} \mathrm{s}^{-1}\right)$ & East & 0.013 & 0.027 & 0.019 \\
\hline & & & North & 0.019 & 0.028 & 0.027 \\
\hline & & Phase lag (h) & East & - & 3.2 & 1.0 \\
\hline & & & North & - & 0.2 & -0.3 \\
\hline & & & East-North & 3.2 & 2.5 & 3.0 \\
\hline & $15 \mathrm{~m}$ water depth & Period (h) & East & 14 & 14 & 14 \\
\hline & & & North & 14 & 14 & 14 \\
\hline & & Amplitude $\left(\mathrm{m} \mathrm{s}^{-1}\right)$ & East & 0.028 & 0.039 & 0.036 \\
\hline & & & North & 0.028 & 0.045 & 0.038 \\
\hline & & Phase lag (h) & East & - & 1.2 & -0.3 \\
\hline & & & North & - & 1.2 & 0 \\
\hline & & & East-North & 3.2 & 3.2 & 3.5 \\
\hline
\end{tabular}

The CCF analysis of the time series of the $15^{\circ} \mathrm{C}$ isotherm indicated a phase lag between the model results and the data of $-0.5 \mathrm{~h}$ for both ELCOM and Delft3D. However, the phase lag of the $10{ }^{\circ} \mathrm{C}$ isotherm was larger in ELCOM $(-1.5 \mathrm{~h})$ compared with that in Delft3D $(-0.5 \mathrm{~h})$. The amplitude of the oscillations of east and north components of the velocities associated with the Poincaré-type wave in the central basin of Upper Lake Constance was larger at $15 \mathrm{~m}$ than at $5 \mathrm{~m}$ depth. This observation was reproduced by ELCOM and Delft3D, with both models showing larger amplitudes of the oscillations of the velocity components at $15 \mathrm{~m}$ than at $5 \mathrm{~m}$ depth. The period of the measured and the simulated oscillatory currents was similar at $15 \mathrm{~m}$ but differed more at the $5 \mathrm{~m}$ depth. In both layers, the agreement of the amplitudes and the periods along the east and north velocity components was higher between the model results than between the models and the data. The phase lags of the Delft3D results was smaller at 5 and $15 \mathrm{~m}$ water depths compared with the results of ELCOM. Furthermore, the phase lag between the east and north velocity components was similar in the data and Delft3D. These results imply that the Delft3D simulation has a marginally higher agreement in phase with the data than the ELCOM simulation, whereas the agreements in period and amplitude with the data are similar for both simulated velocity patterns.

\section{Surface velocity patterns}

Surface velocity patterns were analysed along the drifter paths (Fig. 9e) measured from 14 to 28 August 2009.
Starting from their initial deployment locations (filled circles, Fig. 9e), many drifters propagated within the open water of the central basin of Upper Lake Constance while a few drifted toward the shore areas and to the north (Fig. 9e). The spatial velocity patterns determined along the drifter paths (drifters were deployed at $5 \mathrm{~m}$ water depth) were compared to the velocities simulated at the same locations with the numerical models. Simulated velocities at the locations of the drifters were computed from the modelled velocity field at $5 \mathrm{~m}$ water depth by linear interpolation in time and bilinear interpolation in the horizontal dimension of the velocity components available at a $10 \mathrm{~min}$ time interval and at the $200 \times 200 \mathrm{~m}$ grid cells. Resulting values from ELCOM and Delft3D were compared to the corresponding values of the drifter velocities, and $R^{2}$ and RMSE were calculated considering all velocities derived from the drifter positions.

Velocity values of the east and north components from the measured drifter data and the model simulations were determined (Fig. 9a-d). The cluster of points in the east component generally aligned with the 1:1 relation (dashed line) compared to the cluster of points in the north. In general, the velocities of the east component were larger than those of the north component and had a closer agreement between the 2 models, as indicated by the $R^{2}$ values. Considering all drifter data, the $R^{2}$ between the measured drifter velocities and the respective values from the model simulations was comparatively low for both velocity components (black line). For ELCOM and Delft3D, the $R^{2}$ was 0.26 and 


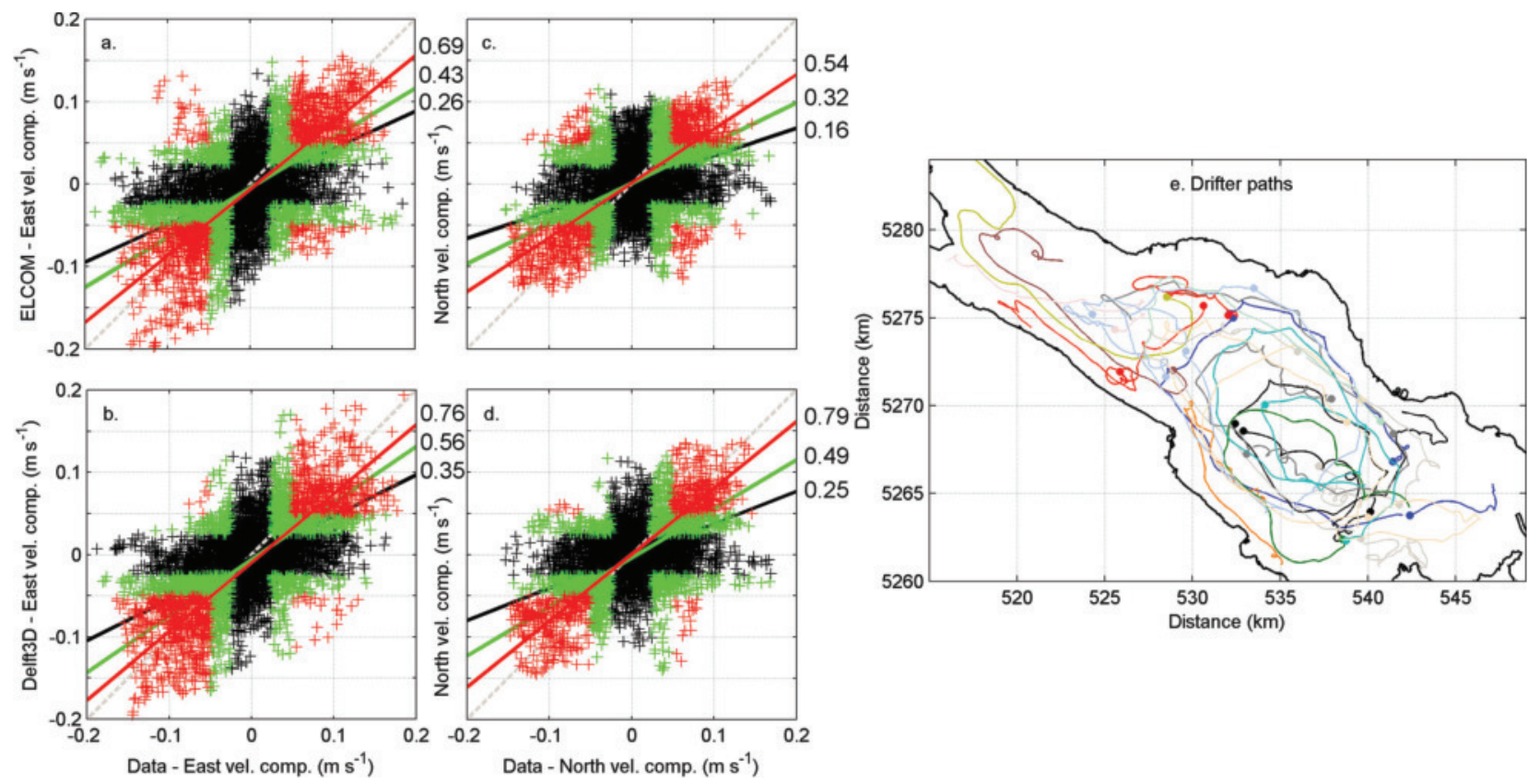

Figure 9. Agreement $\left(R^{2}\right)$ of the surface pattern between the measured drifter velocities and the simulated velocities; (a) measured ELCOM east velocity, (b) measured Delft3D east velocity, (c) measured ELCOM north velocity, and (d) measured Delft3D north velocity. $x$-axis: measured, $y$-axis: simulated; Dashed line: 1:1 relation; black line: all measured drifter velocities; green line: drifter velocities exceeding $0.025 \mathrm{~m} \mathrm{~s}^{-1}$; and red line: drifter velocities exceeding $0.050 \mathrm{~m} \mathrm{~s}^{-1}$. Numbers indicate linear regression $\left(R^{2}\right)$ for the respective line. (e) Measured drifter paths. The colour coding indicates different drifter paths and the filled circles the location of the initial deployment.

0.35 for the east components and 0.16 and 0.25 for the north components, respectively. However, the $R^{2}$ for results from both models and for both velocity components increased substantially if only higher velocities of the components were considered that exceeded a threshold of $0.025 \mathrm{~m} \mathrm{~s}^{-1}$ (green line) and of $0.050 \mathrm{~m} \mathrm{~s}^{-1}$ (red line) with respect to the drifter data (Fig. 9). In general, the agreement between simulations and data was slightly closer for the simulated results from Delft3D than from ELCOM.

Simulated surface velocity magnitude and direction were compared with the drifter data for different classes of velocities (Fig. 10). The normalised velocity difference of ELCOM (Fig. 10a) had the highest deviation of velocities within the lowest velocity class from 0 to $0.025 \mathrm{~m} \mathrm{~s}^{-1}$. As the velocity increased, the deviation and the median of the normalised velocity difference decreased. The lowest deviation of velocities was found within the highest velocity class $(0.175-0.250 \mathrm{~m}$ $\mathrm{s}^{-1}$ ). A similar trend was found for Delft3D (Fig. 10b). Note, however, that the median values of Delft3D in each velocity class were marginally lower than those of ELCOM. Directional difference in the velocities between ELCOM and the drifter data also showed a decreasing trend in the deviation and the median as the velocity increased (Fig. 10c). In the higher velocity classes, some outliers were observed, but they had no effect on the general trend in which higher velocity classes have lower deviations than those of the lower velocity classes. Similar characteristics were found for the directional difference of Delft3D (Fig. 10d). The normalised velocity difference and the directional difference indicated that both ELCOM and Delft3D resulted in similar agreement with the drifter data. These agreements were higher during higher velocities than lower velocities.

The estimated velocity magnitudes along the drifter paths (position and time recorded by the drifters; Fig. 11a) corresponded to different temporal and spatial points during the drifter experiments, and thus the spatial pattern does not represent a simultaneous pattern of the velocity magnitudes. About $70 \%$ of the measured velocities were higher than $0.05 \mathrm{~m} \mathrm{~s}^{-1}$. The velocities higher than $0.15 \mathrm{~m} \mathrm{~s}^{-1}$ accounted for $\sim 6 \%$ of all observations and typically occurred in the vicinity of the lake shores (Fig. 11a). Drifter paths accompanied by high velocities tended to be straighter than the drifter paths with low velocities. Although the model performance was better during high velocities, the highest RMSE values corresponded to the high velocity magnitudes of the drifters, which generally occurred close to the lake shores. The estimated RMSE values along the main 

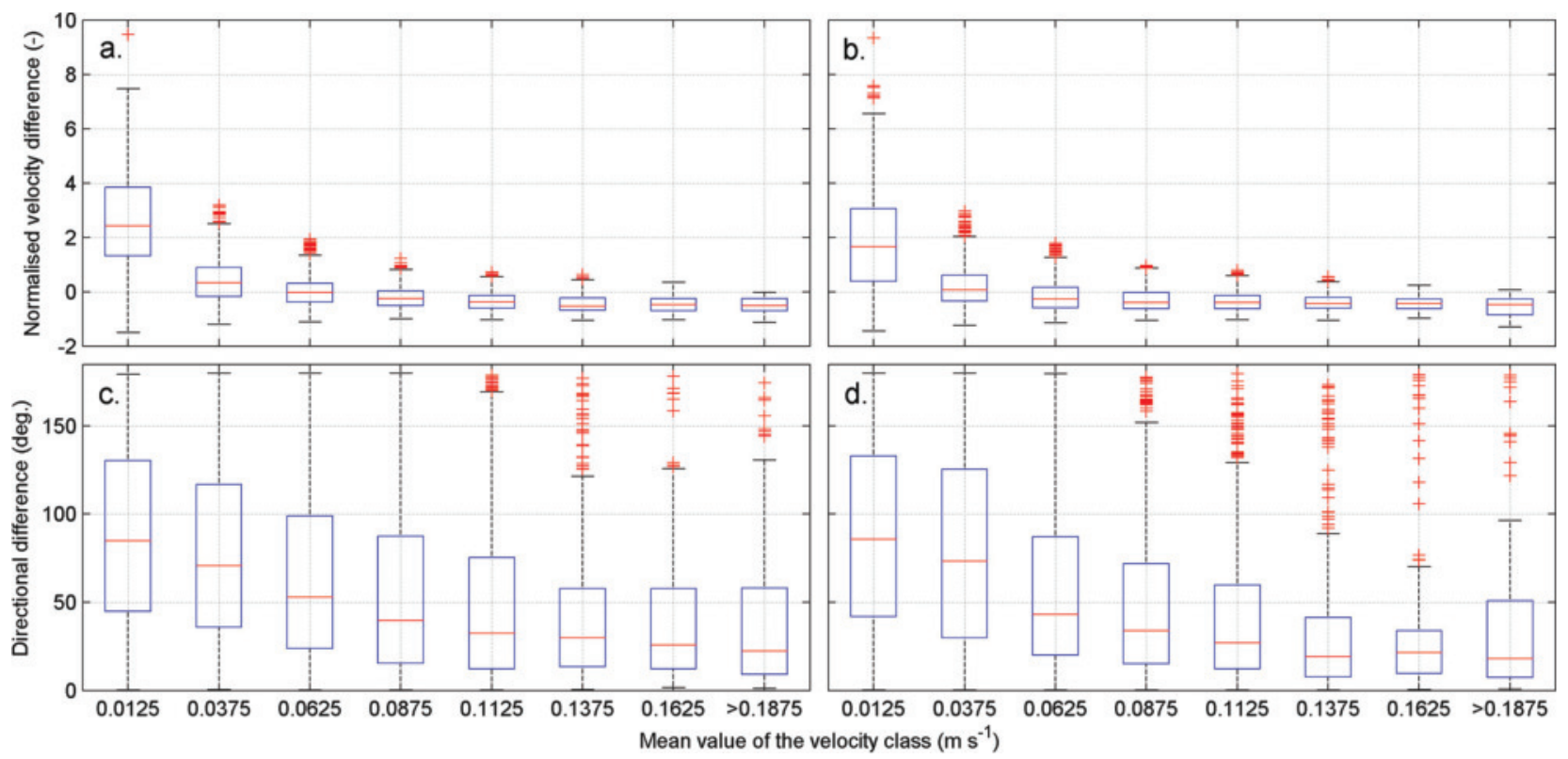

Figure 10. Comparison of surface velocity by estimating the (a) and (b) normalised velocity difference (ELCOM and Delft3D) and (c) and (d) directional difference (ELCOM and Delft3D) between the measured drifter velocities and the simulated velocities.

horizontal axis of Upper Lake Constance were below $0.05 \mathrm{~m} \mathrm{~s}^{-1}$ in both ELCOM and Delft3D (Fig. 11b-c). About $22 \%$ of the RMSE in ELCOM was higher than $0.05 \mathrm{~m} \mathrm{~s}^{-1}$ but $\sim 36 \%$ in Delft3D. Therefore, the comparison of the velocity magnitude with RMSE indicates that ELCOM more closely agreed with the drifter velocity than that in Delft3D, although the comparison of the velocity components separately (Fig. 9) indicated a closer agreement with Delft3D.

The agreement between the model-simulated circulations was estimated within the drifter area by analysing the normalised difference ( $D$ in equation 3 ) of the horizontal velocity components at $5 \mathrm{~m}$ water depth during the period of the drifter experiment from 14 to 28 August 2009. The highest and lowest values of D during this period were selected as the representative time points to illustrate the worst (largest deviation) and best (smallest deviation) agreement of the horizontal circulation patterns predicted by the 2 models.

The highest value of $\mathrm{D}$ (6.9) was found on 17 August at $0135 \mathrm{~h} \mathrm{(t1)} \mathrm{and} \mathrm{the} \mathrm{lowest} \mathrm{(0.5)} \mathrm{on} 24$ August at 1815 h (t2, Fig. 12). At t1, the simulated horizontal velocity fields were different between ELCOM and Delft3D. In ELCOM (upper left panel, blue vectors, Fig. 12), the main current at the southern boundary of the lake was directed southeast. Close to the northern shore and toward the central part of the basin, the model developed 2 gyres rotating in opposite directions. At the eastern part of the lake, the current was directed toward the shore. These features are in contrast to the current field simulated with Delft3D (upper right panel, black vectors, Fig. 12). A dominant southeast-directed current pattern was only found in the north of the main basin. In Delft3D, the velocities
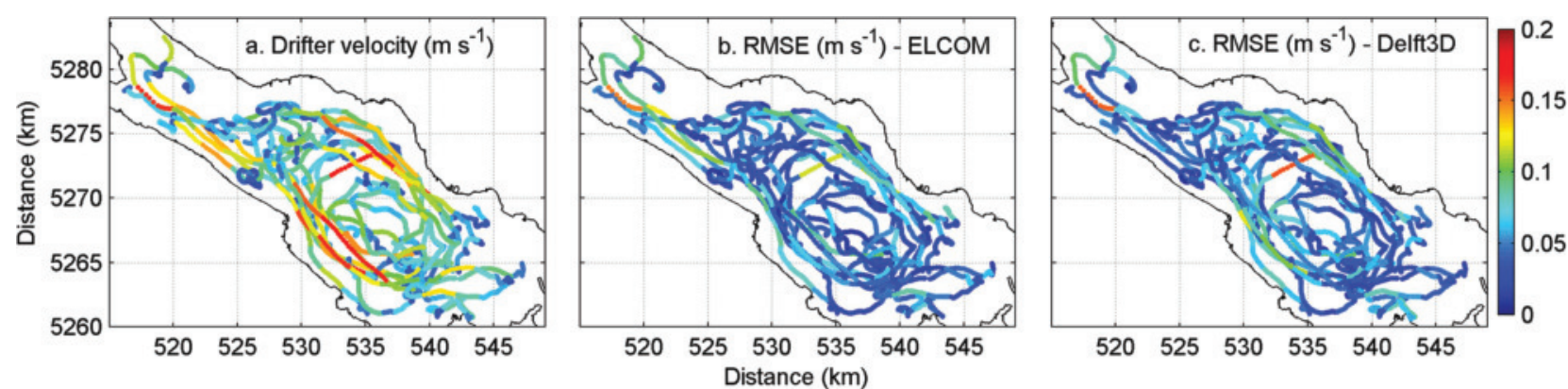

Figure 11. Comparison of drifter velocity magnitudes with the simulated velocity magnitudes by estimating the RMSE values: (a) measured drifter velocity magnitude, (b) RMSE of ELCOM, and (c) RMSE of Delft3D. The colour coding indicates the velocity magnitude ( $\mathrm{m} \mathrm{s}^{-1}$ ). 


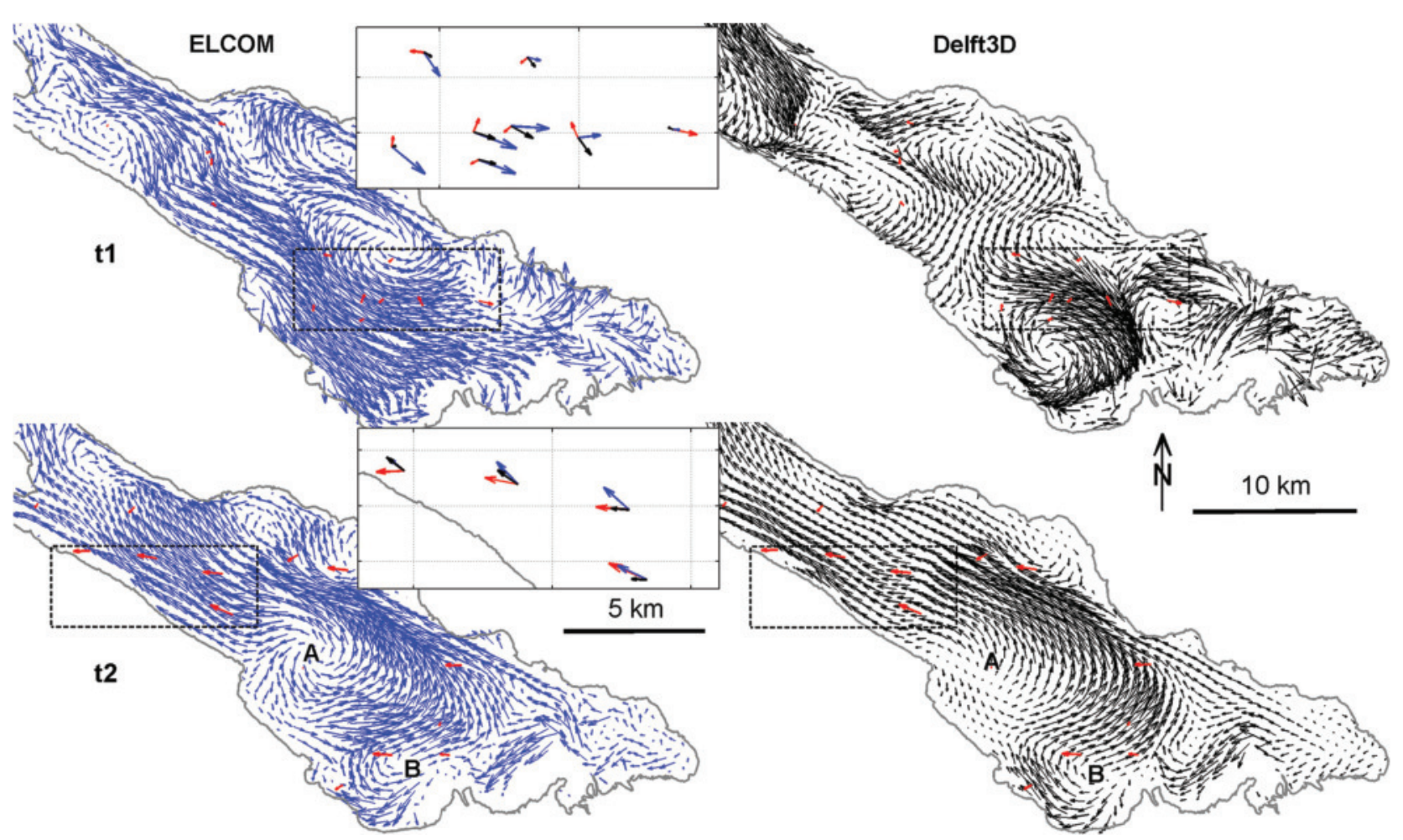

Figure 12. Horizontal current field at $5 \mathrm{~m}$ water depth in ELCOM and Delft3D for 2 selected times (t1: 17 August at $0135 \mathrm{~h}$, having the poorest agreement, and t2: 24 August at $1815 \mathrm{~h}$, having the best agreement between simulated current velocities) in combination with the corresponding drifter velocity vectors (red arrows). Zoom-out views show velocity vectors from the 2 models and the drifters together (ELCOM: blue; Delft3D: black; and drifter velocities: red). Note that the simulated velocity vectors are drawn at a subset of the grid points for clarity. A and B show locations with circulation patterns with different velocities in ELCOM and Delft3D.

simulated in the middle of the lake were weaker than in ELCOM, and the spatial orientation was also different. A clockwise rotating eddy developed in the southern part of the basin. In the eastern part of the basin, the current was directed in the opposite direction than in ELCOM. At t2, the agreement of the horizontal velocity fields simulated with ELCOM and Delft3D was improved. Both current fields showed a counterclockwise circulation in the middle of the basin, with higher velocities in the north than in the south (indicated by A in the lower 2 panels of Fig. 12). However, the velocities in Delft3D were weaker than in ELCOM, particularly in the south area of A. The main current pattern was oriented northwest in both models. Furthermore, a small clockwise rotating eddy appeared in both models at the south of the basin (indicated by $B$ in the lower 2 panels of Fig. 12).

The velocity vectors from both simulations and from the drifter experiments were selected at $\mathrm{t} 1$ and $\mathrm{t} 2$ based on the availability of the drifter data (Fig. 12). At t1, the time point when the 2 models disagree most with each other, the simulated velocity vectors of the 2 models seemingly agree better with each other than with the drifter data. At $\mathrm{t} 2$, the simulated velocity vectors agree well between models and with the measured velocity vectors (Fig. 12).

\section{Discussion}

Validation of 3D hydrodynamic models is predominantly based on time series of temperature profiles (e.g., Antenucci et al. 2000, Antenucci and Imberger 2001, Appt et al. 2004) or current profiles (e.g., Razmi et al. 2014, Niu et al. 2015) at a few stations in lakes. At the spatial dimensions of most lakes, surface heat fluxes vary little spatially, and therefore time-averaged temperature stratification is essentially homogeneous in the horizontal dimension. However, vertical displacements of the thermocline due to internal waves cause temperature oscillations and horizontal differences in temperature (Wüest and Lorke 2003). Performance tests of hydrodynamic models based on the time series of vertical temperature profiles are therefore sensitive to the model skills with respect to the prediction of mean stratification (i.e., the quality of the heat fluxes at the lake surface and the vertical mixing) and to the simulation of internal wave motions, in particular the simulation of internal seiches. Investigation of model skills 
based on current profiles is also sensitive to the simulation of motions generated by seiches because these motions are associated with comparatively large currents throughout the water column. Furthermore, currents due to internal wave have an oscillatory behaviour, which makes them a dominant feature affecting qualitative model evaluation by visual comparison. Hence, model evaluation based on vertical temperature and current profiles is easily dominated by the model performance with respect to the simulation of seiches and may be less sensitive to the performance of the model with respect to surface circulation.

Our model simulations of Upper Lake Constance captured regular oscillatory patterns in isotherms (Fig. 4) and velocity structures (Fig. 7). Different wave types of internal seiches exist in Upper Lake Constance, particularly Kelvin-type and Poincaré-type (Appt et al. 2004). Bäuerle et al. (1998) determined that the most dominant Kelvin-type wave in Upper Lake Constance has a vertical mode-one oscillation, and Appt et al. (2004) showed that the vertical displacements due to Kelvin waves are especially pronounced in Lake Überlingen. In Upper Lake Constance, Poincaré-type waves have maximal velocity amplitudes in the centre of the main basin of Upper Lake Constance (Wang et al. 2000).

The estimated heat fluxes at S1 (Lake Überlingen) using the field data and the empirical relations of each model showed close agreement between ELCOM and Delft3D, indicating that although the models used different empirical relations for the heat fluxes, the overall heat flux into the lake was similar. The vertical temperature profiles measured during strong stratification in summer at the middle of Lake Überlingen (S1) confirmed the oscillatory patterns of isotherms, indicating characteristics of the basin-scale internal waves (Appt et al. 2004). The simulated temperature distributions of both models, ELCOM and Delft3D, were characterized by isotherm oscillations that closely agreed with the major oscillatory patterns in the data caused by the dominant basin-scale internal waves. Apart from the major oscillatory pattern, the data further indicated minor oscillations of isotherms at frequencies higher than $10^{-5} \mathrm{~Hz}$ as well as events of high frequency internal waves (e.g., on 12 and 26 August; Fig. 3c). The high frequency internal waves were not reproduced by the model simulations, whereas the relatively smooth minor oscillations were captured by the models. The horizontal discretisation of the model domain $(200 \times 200 \mathrm{~m})$ was too coarse to resolve the oscillations due to high frequency internal waves. Moreover, the spatial $(\sim 2.2 \mathrm{~km})$ and temporal $(1 \mathrm{~h})$ resolution of the imposed wind field limited capturing small-scale features such as characteristics generated by thermally driven wind (Lorrai et al. 2011).
PSD analysis on the temporal course of the 2 isotherms derived from the thermistor chain (10 and $15{ }^{\circ} \mathrm{C}$; Fig. 4) during August (summer) identified a dominant peak at $84 \mathrm{~h}$ and a secondary peak at $14 \mathrm{~h}$. Both models captured the dominant peak, as in the data, whereas the secondary peak occurred at $11 \mathrm{~h}$. The dominant peak corresponds to a vertical mode-one Kelvin-type wave and the second peak indicates a vertical mode-one Poincaré-type wave. During autumn, Bäuerle et al. (1998) observed Kelvin-type internal waves with periods ranging between 90 and $120 \mathrm{~h}$ in Lake Überlingen. Furthermore, during October and November (autumn), Appt et al. (2004) observed internal waves in the same basin, a Kelvin-type wave with a period of $90 \mathrm{~h}$, and a Poincaré-type wave with a period of $12 \mathrm{~h}$. At the centre of Upper Lake Constance, Wang et al. (2000) showed the occurrence of a $\sim 12 \mathrm{~h}$ Poincaré-type wave. These observations indicate that the wave period depends on the time period of the observation in which the lake experiences different stratification and thus thickness of the upper mixed layer. The modelled stratification may differ from the true stratification in a lake because simulated heat fluxes and vertical mixing may be under- or overestimated because of uncertainty in the meteorological data and in the empirical relation for the heat flux model. Furthermore, in this case the simulated internal seiches, and thus the simulated oscillations of the isotherms and currents, differ from the observations even if the imposed horizontally resolved wind field is correct. However, erroneous wind fields can also cause deviations between the observations and the model results. Average temperature profiles and isotherm displacements showed higher agreement between ELCOM and Delft3D than between the models and the data. The better agreement between simulations with different models than between simulations and data suggests that the model input meteorological parameters have been more limiting in predicting the observed isotherm displacements than the specific differences between the numerical formulations of ELCOM and Delft3D (Appendix A).

Existence of different Poincaré-type waves has been previously observed by analysing measured temperature profiles during autumn close to the shore areas in Upper Lake Constance (Appt et al. 2004). However, the Poincaré-type waves are typically more pronounced in the middle of lakes (Wang et al. 2000) and much more visible in the current velocity than in the temperature profiles (Imboden and Wüest 1995). The velocity measurements used in this study were carried out during summer at S2 in the middle of Upper Lake Constance. Comparison of velocity variation at 3 depth levels (5, 10 , and $15 \mathrm{~m}$ ) showed different agreements between the models and the data. At the deep layers (10 and 
$15 \mathrm{~m}$ water depth), the oscillatory pattern of the velocities was more regular than in the layers close to the surface (e.g., at $5 \mathrm{~m}$ water depth; Fig. 7). The internal wave structure dominated in the deep layers, whereas the oscillations close to the surface were the result of a superposition of internal wave motions and currents due to direct wind forcing (Imberger and Patterson 1990, Imboden and Wüest 1995, Wüest et al. 2000, Wüest and Lorke 2003). The agreement of current velocities increased from surface to deep layers (i.e., from 5 to 10 to $15 \mathrm{~m}$ water depth) between the simulations and the data as well as between ELCOM and Delft3D. The higher discrepancy between the 2 models near the water surface is probably because they estimate wind shear using different coefficients for the widely used quadratic expression (Hodges and Dallimore 2006, Deltares 2014). Delft3D uses 3 wind-drag coefficients compared to 1 wind-drag coefficient in ELCOM to estimate the wind shear based on wind speeds. Statistical analyses using ACF, CCF, and band-pass filters clearly indicated the comparisons of amplitude, period, and phase of the Kelvin-type (based on vertical displacement of isotherm) and Poincaré-type (based on velocity variation) waves between the model results and the data and between the model results (Table 3 ). The model simulations were able to reproduce the Poincaré-type wave period (14 h), as in the measured data, using velocities in the middle of the basin. The oscillations of isotherms associated with the Kelvin wave and the oscillations of the velocity components associated with the Poincaré waves had higher amplitudes in the layer at $15 \mathrm{~m}$ than at $5 \mathrm{~m}$. Furthermore, the agreement between the data and the models as well as between the models was higher at $15 \mathrm{~m}$ than that $5 \mathrm{~m}$ depth. Therefore, focusing on layers below the surface mixed layer when analysing internal wave patterns is advantageous because the surface layers are much more sensitive to the direct influence of the wind field in addition to the internal wave surface currents. Both ELCOM and Delft3D can reproduce the major oscillations of the observed Kelvin-type and Poincaré-type waves with little difference in performance between the 2 models.

Comparison of surface velocity magnitudes at $5 \mathrm{~m}$ water depth using the coefficient of determination $\left(R^{2}\right)$ showed that the agreement between the simulations and the derived data from the drifters increased for higher current velocities $\left(>0.05 \mathrm{~m} \mathrm{~s}^{-1}\right)$. During low and moderate wind speeds, weaker agreements than during strong winds were also observed between the drifter and the model-simulated velocities in ocean drifter experiments, such as the East Mediterranean Sea (Poulain et al. 2009) and German Bight-North Sea (Callies et al. 2017). The simulated large circulation patterns in
ELCOM and Delft3D qualitatively showed higher agreement when the drifter velocities were high (e.g., t2, red arrow in the zoom-out view of Fig. 12) and lower agreement when the drifter velocities were weak (e.g., t1). Estimation of wind shear on the water surface may contribute to the observed differences between ELCOM and Delft3D. We used $C_{d}=0.0013$ in ELCOM but 0.0019 in Delft3D (note: wind velocity during the simulation period did not exceed $100 \mathrm{~m} \mathrm{~s}^{-1}$, so we did not use $\mathrm{C}_{\mathrm{d}}=0.0723$; see Table 1). Therefore, Delft3D should have estimated higher wind shear stress on the water surface, leading to higher velocities than those in ELCOM. However, according to the drifter results, the agreement between models is closer than the agreement between the models and the drifter data. This means factors other than the effect of wind drag coefficient employed in the models are affecting the comparison of the drifter velocities and the simulated velocities. For example, the estimated drifter velocities could differ from the actual surface velocities by slipping of drifters due to direct aerodynamic force acting on the surface buoy of the drifters (Poulain et al. 2009). Our analysis implies that the currents from drifters and simulations more closely agree for large currents than for small currents, partly because of slipping effects of the drifters, whereas it is also consistent with the hypothesis that the wind field at weak wind speeds is less reliable than at strong wind speeds. During strong winds, not only larger currents can be expected but also smaller variation in wind direction than during weak winds at short temporal scales. Hence, the wind field, especially during times of comparatively weak winds, may be important for the fluctuations of the current field and thus variations of drifter paths near the surface. However, wind speeds, and in particular wind directions, are most likely less reliable during weak winds than during strong winds, emphasising the importance and needs of reliable and spatially highly resolved wind fields to accurately simulate the lake hydrodynamics.

\section{Conclusions}

The models ELCOM and Delft3D have different empirical formulations for estimating heat fluxes at the water surface of lakes. However, the simulated temperature structures showed closer agreement between ELCOM and Delft3D than between the models and the data. Both ELCOM and Delft3D resulted in similar total heat flux in Lake Überlingen, a basin of Lake Constance. Averaged vertical temperature profiles during the evaluation period showed that the model-estimated temperature in the upper mixed layer (up to $5 \mathrm{~m}$ water depth) was higher than the observed temperature (maximum 
$\sim 1{ }^{\circ} \mathrm{C}$ ) while that of ELCOM was higher by $\sim 0.5^{\circ} \mathrm{C}$ than Delft3D. Simulated oscillatory patterns of isotherms indicated the occurrence of 2 basin-scale waves in Lake Überlingen as observed in the data. The vertical modeone Kelvin-type wave had a period of $84 \mathrm{~h}$ in both simulated and the measured data. The period of the vertical mode-one Poincaré-type wave was $14 \mathrm{~h}$ in the measured data but only $11 \mathrm{~h}$ in both models. Analyses on the measured and the simulated current patterns further showed the agreement between ELCOM and Delft3D. The measured vertical velocity structure in the main basin of Upper Lake Constance also showed the existence of a $14 \mathrm{~h}$ Poincaré-type wave. ELCOM and Delft3D captured the $14 \mathrm{~h}$ period in the current velocity. Both models marginally overpredicted the velocity magnitude compared to the data. Velocity fluctuations associated with the Poincaré-type wave simulated with ELCOM had a larger phase shift to the data than Delft3D simulations. Currents in the upper $5 \mathrm{~m}$ of the water column often showed discrepancies between the simulated velocities and also between the simulated and the measured velocities. The dynamics in the surface layers are characterized by the superposition of currents due to direct wind forcing at the free surface and the baroclinic dynamics due to internal waves, whereas the dynamics in the deep layers are dominated by currents caused by internal waves. Model validation based on the comparison of isotherm displacement and oscillatory current patterns, which predominantly reflects the internal wave motions, does not necessarily support the model performance with respect to surface currents and horizontal transport in the surface layers. The agreement between the velocities derived from the drifter data and the simulated velocities increased with the magnitude of drifter velocity. Possibly, the wind forcing, especially the direction of forcing, is more reliable at high than at low wind speeds.

ELCOM and Delft3D had similar model performance in simulating baroclinic dynamics and surface currents during a stratified period in Upper Lake Constance. In general, properties of the internal wave field, in particular wave periods and amplitudes, simulated by both models had close agreement with the measured data. Details of the flow field in the upper mixed, windaffected surface layer were captured much better by the models at large currents than at low currents, suggesting that wind fields at low currents (i.e., typically at low wind speeds) are less reliable than at high wind speeds. Generally, the deviation between the data and the simulated results was larger than between the simulated results of ELCOM and Delft3D, suggesting that both models are equally capable in the simulation of the stratification and flow field in lakes. The overall deviations between the simulated and the measured flow field and stratification not only depend on the parameterization of the hydrodynamic model but also on the imprecisions in the wind field. Thus, validation of model performance and model comparisons may strongly benefit from the availability of independently derived, horizontally resolved wind fields above the lake surface.

\section{Acknowledgements}

The authors acknowledge National Swiss Weather Service (MeteoSwiss) for providing access to wind data from the high-precision numerical weather prediction system of the Consortium for Small-Scale Modeling (COSMO) and German Weather Service (DWD) for providing wind data from the station Konstanz. Further, the authors thank Georg Heine, Bruno Erne, and their colleagues from the electronic and mechanical workshop at University of Konstanz for the technical assistance to develop the drifters. The authors gratefully acknowledge the support of the technical staff at Limnological Institute, Martina Preuße, and many students during fieldwork and data analysis. The authors further appreciate the support by the local authorities: Internationale Gewässerschutzkommission für den Bodensee (IGKB), Institute for Lake Research in Langenargen (ISF), and Rural District Offices in Germany and Switzerland. This work was financially supported by the Province of Baden-Wuerttemberg (BWPlus) and the Federal Ministry of Education and Research (BMBF-ReWaM Collaborative Research Project - HyMoBioStrategie). The authors finally acknowledge 2 anonymous reviewers and the editor for the constructive comments, which further improved the manuscript.

\section{ORCID}

Pushpa Dissanayake (D) http://orcid.org/0000-0003-2159-9940 Hilmar Hofmann (D) http://orcid.org/0000-0001-6140-5886

Frank Peeters (D) http://orcid.org/0000-0002-9387-7017

\section{References}

Antenucci J, Imberger J, Saggio A. 2000. Seasonal evolution of the basin-scale internal wave field in a large stratified lake. Limnol Oceanogr. 45:1621-1638.

Antenucci J, Imberger J. 2001. On internal waves near the high-frequency limit in an enclosed basin. J Geophys Res. 106:22465-22474.

Appt J, Imberger J, Kobus H. 2004. Basin-scale motion in stratified Upper Lake Constance, Limnol Ocenogr. 49(4):919933.

Bäuerle E, Ollinger D, Ilmberger J. 1998. Some meteorological, hydrological, and hydrodynamical aspects of Upper Lake Constance. Arch Hydrobiol Adv Limnol. 53:31-83.

Becherer JK, Umlauf L. 2011. Boundary mixing in lakes: 1. Modeling the effect of shear-induced convection. J Geophys Res. 116:C10017.

Beletsky D, O’Connor WP, Schwab DJ, Dietrich DE. 1997. Numerical simulation of internal Kelvin waves and coastal upwelling fronts. J Phys Oceanogr. 27:1197-1215. 
Boyce FM, Donelan MA, Hamblin PF, Murthy CR, Simos TJ. 1989. Thermal structure and circulation in the Great Lakes. Atmos Ocean. 27(4):607-642.

Callies U, Groll N, Horstmann J, Kapitza H, Klein H, Maßmann S, Schwichtenburg F. 2017. Surface drifters in the German Bight: model validation considering windage and Stokes drift. Ocean Sci Discuss. 13(5):1-38.

Casulli V, Cheng RT. 1992. Simi-implicit finite difference methods for three-dimensional shallow water flow. Int J Numer Method Fluid. 15:629-648.

Deltares. 2014. Simulation of multi-dimensional hydrodynamic flows and transport phenomena, including sediments. User manual, hydro-morphodynamics, ver. 3.15.

Fischer HB, List EG, Koh RCY, Imberger J, Brooks NH. 1979. Mixing in inland and coastal waters. New York: Academic.

Gómez-Giraldo A, Imberger J, Antenucci JP. 2006. Spatial structure of the domain basin-scale internal waves in Lake Kinneret. Limnol Oceanogr. 51(1):229-246.

Henderson-Sellers B. 1986. Calculating the surface energy balance for lake and reservoir modelling: a review. Rev Geophys. 24(3):625-649.

Hodges BR, Dallimore C. 2006. Estuary, lake and coastal ocean model: ELCOM, v2.2 Science Manual. Perth (Australia): University of Western Australia, Centre for Water Resources. Technical Publication.

Hodges BR, Imberger J, Saggio A, Winters KB. 2000. Modelling basin scale internal waves in a stratified lake. Limnol Oceanogr. 45(7):1603-1620.

Huang A, Rao YR, Lu Y. 2010a. Evaluation of a 3D hydrodynamic model and atmospheric forecast forcing using observations in Lake Ontario. J Geophys Res. 115(C02004):1-13.

Huang A, Rao YR, Lu Y, Zhao J. 2010b. Hydrodynamic modelling of Lake Ontario: an intercomparison of three models. J Great Lakes Res. 115:C12076.

Huss E, Stranz D. 1970. Die Windverhältnisse am Bodensee [Wind conditions at Lake Constance]. Pure Appl Geophys. 81:323-356.

Imberger J, Patterson JC. 1981. A dynamic reservoir simulation model-DYRESM 5. In: Fischer $\mathrm{H}$, editor. Transport models for inland and coastal waters. New York: Academic Press; p. 310-361.

Imberger J, Patterson JC. 1990. Physical limnology. Adv Appl Mech. 27:303-475.

Imboden DM, Wüest A. 1995. Mixing mechanisms in lakes. In: Lerman A, Imboden DM, Gat JR, editors. Physics and chemistry of lakes, 2nd ed. New York (NY):Springer; p. $83-112$

Iziomon MG, Mayer H, Matzarak A. 2003. Downward atmospheric longwave irradiance under clear and cloudy skies: measurement and parameterization. J Atmos Sol-Terr Phy. 65:1107-1116.

Jacquet J. 1983. Simulation of the thermal regime of rivers. In: Orlob GT, editor. Mathematical modelling of water quality: streams, lakes and reservoirs. Hoboken (NJ): WileyInterscience.

Koue J, Shimadera H, Matsuo T, Kondo A. 2018. Evaluation of thermal stratification and flow field reproduced by a threedimensional hydrodynamic model in Lake Biwa, Japan. Water. 10(1):47.

Krause P, Boyle DP, Bäse F. 2005. Comparison of different efficiency criteria for hydrological model assessment. Adv Geosci. 5:89-97.
Laborde S, Antenucci JP, Copetti D, Imberger J. 2010. Inflow intrusions at multiple scales in a large temperate lake. Limnol Oceanogr. 55(3):1301-1312.

Livingstone DM, Imboden DM. 1989. Annual heat balance and equilibrium temperature of Lake Aegeri, Switzerland. Aquat Sci. 51(4):351-369.

Lorrai C, Umlauf L, Becherer JK, Lorke A, Wüest A. 2011. Boundary mixing in lakes: 2. Combined effects of shearand convectively induced turbulence on basin-scale mixing. J Geophys Res. 116(C10018):1-12.

Murakami M, Oonisishi Y, Kunishi H. 1985. A numerical simulation of the distribution of water temperature and salinity in the Seto Inland Sea. J Oceanogr Soc Japan. 41:221-224.

Nguyen TD, Thupaki P, Anderson EJ, Phanikumar MS. 2014. Summer circulation and exchange in the Saginaw Bay-Lake Huron system. J Geophys Res Oceans. 119:1713-1734.

Niu Q, Meng X, Rutherford ES, Mason DM, Anderson EJ, Schwab DJ. 2015. Investigation of interbasin exchange and interannual variability in Lake Erie using an unstructuredgrid hydrodynamic model. J Geophys Res Oceans. 120:2212-2232.

Ollinger D. 1999. Modellierung von temperatur, turbulenz und algenwachstum mit einem gekoppelten physikalisch-biologischen modell [Modeling of temperature, turbulence and algae growth using a coupled physical-biological model]; [dissertation]. Heidelberg (Germany): Ruprecht-KarlsUniversität.

Peeters F, Hofmann H. 2015. Length-scale dependence of horizontal dispersion in the surface water of lakes. Limnol Oceanogr. 60(6):1914-1934.

Poulain PM, Gerin R, Mauri E, Pennel R. 2009. Wind effects on drogued and undrogued drifters in the Eastern Mediterranean. J Atmos Ocean Tech. 26:1144-1156.

Rao YR, Marvin CH, Zhao J. 2009. Application of a numerical model for circulation, temperature and pollutant distribution in Hamilton Harbour. J Great Lakes Res. 35:61-73.

Razmi AM, Barry DA, Bakhtyar R, Le Dantec N, Dastgheib A, Lemmin U, Wüest A. 2013. Current variability in a wide and open lacustrine embayment in Lake Geneva (Switzerland). J Great Lakes Res. 39:455-465.

Razmi AM, Barry DA, Lemmin U, Bonvin F, Kohn T, Bakhtyar R. 2014. Direct effects of dominant winds on residence and travel times in the wide and open lacustrine embayment: Vidy Bay (Lake Geneva, Switzerland). Aquat Sci. 76(Suppl. 1):59-71.

Rodi W. 1984. Turbulence models and their application in hydraulics: a state-of-the-art review. The Netherlands: International Association for Hydraulic Research.

Schättler U. 2009. A description of the nonhydrostatic regional COSMO-Model Part V. Preprocessing: initial and boundary data for the COSMO-Model. http://www.cosmo-model.org.

Shimizu K, Imberger J, Kumagai M. 2007. Horizontal structure and excitation of primary motions in a strongly stratified lake. Limnol Oceanogr. 52:2641-2655.

Smith SD, Banke EG. 1975. Variation of the sea surface drag coefficient with wind speed. Q J Roy Meteorol Soc. 101:665-673.

Song Y, Semazzi FHM, Xie L, Ogallo LJ. 2004. A coupled regional climate model for the Lake Victoria Basin of East Africa. Int J Climatol. 24:57-75.

Stelling GS. 1984. On the construction of computational methods for shallow water flow problem. Rijkswaterstaat 
Communications, vol. 35. The Hague (Netherlands): Governing Printing Office.

Stelling GS, Duinmeijer SPA. 2003. A staggered conservative scheme for every Froude number in rapidly varied shallow water flows. Int J Numer Meth Fluid. 43:1329-1354.

Uittenbogaard RE, Van Kester JATM, Stelling GS. 1992. Implementation of three turbulence models in 3DTRISULA for rectangular grids. Report Z81. Delft (Netherlands): Delft Hydraulics.

Umlauf L, Lemmin U. 2005. Interbasin exchange and mixing in the hypolimnion of a large lake: the role of long internal waves. Limnol Oceanogr. 50(5):1601-1611.

Van Leer B. 1974. Towards the ultimate conservative difference scheme II. Monotonicity and conservation combined in a second order scheme. J Comput Phys. 32:101-136.

Wahl B, Peeters F. 2014. Effect of climate change on stratification and deep-water renewal in Lake Constance assessed by sensitivity studies with a 3D hydrodynamic model. Limnol. Oceanogr. 59(3):1035-1052.

Wang Y, Hutter K, Bäuerle E. 2000. Wind-induced baroclinic response of Lake Constance. Annu Geophys. 18:1488-1501.

Wüest A, Lorke A. 2003. Small-scale hydrodynamics in lakes. Annu Rev Fluid Mech. 35:373-412.

Wüest A, Piepke G, van Senden DC. 2000. Turbulent kinetic energy balance as a tool for estimating vertical eddy diffusivity measured by tracer and microstructure techniques, Dyn Atmos Oceans. 24:27-39.

\section{Appendix A: Model formulations and abbreviations in the heat flux estimation of ELCOM and Delft3D}

The total heat energy transfer across the free surface $\left(H_{t o t}\right)$ is separated into penetrative short wave radiation, non-penetrative components of long-wave radiation, convective heat transfer (sensible), and evaporative heat loss (latent). Non-penetrative effects are introduced as sources of temperature in the surface layer, whereas penetrative effects are introduced as source terms in one or more grid layers on the basis of an exponential decay and an extinction coefficient in both models ELCOM and Delft3D. The heat flux from atmosphere to water surface is positive and that from water surface to atmosphere is negative:

$$
H_{\text {tot }}=H_{\mathrm{s}}+\left(H_{\mathrm{A}}-H_{\mathrm{W}}\right)-H_{\mathrm{E}}-H_{\mathrm{C}},
$$

where, the heat fluxes are:

\footnotetext{
$H_{s} \quad$ net solar radiation (short wave; $\mathrm{J} \mathrm{m}^{-2} \mathrm{~s}^{-1}$ )

$H_{A} \quad$ atmospheric radiation (long wave; $\mathrm{J} \mathrm{m}^{-2} \mathrm{~s}^{-1}$ )

$H_{W} \quad$ back radiation from the water surface (long wave; $\mathrm{J} \mathrm{m}^{-2} \mathrm{~s}^{-1}$ )

$\left(H_{A}-H_{\mathrm{W}}\right)$ net long wave radiation from atmosphere to water surface $\left(\mathrm{J} \mathrm{m}^{-2} \mathrm{~s}^{-1}\right)$

$H_{E} \quad$ evaporative heat flux (latent heat; $\mathrm{J} \mathrm{m}^{-2} \mathrm{~s}^{-1}$ )

$H_{C} \quad$ convective heat flux (sensible heat; $\mathrm{J} \mathrm{m}^{-2} \mathrm{~s}^{-1}$ )
}

\section{Net solar radiation $\left(\mathrm{H}_{\mathrm{S}}\right)$}

ELCOM estimates the net solar radiation penetrating into the water column as described in Jacquet (1983):

$$
\begin{gathered}
H_{\mathrm{s}}=H_{\mathrm{s}, \mathrm{tot}}\left(1-r_{a}^{\mathrm{sw}}\right), \\
r_{a}^{\mathrm{sw}}=R_{a}^{s w}+a_{s w} \sin \left(\frac{2 \pi \mathrm{d}}{\mathrm{D}}+\frac{\pi}{2}\right) .
\end{gathered}
$$

The depth of penetration is estimated according to the Lambert-Beer's law that depends on a user-defined extinction coefficient:

$$
H_{s}(h)=H_{s} \mathrm{e}^{-\eta_{a} h},
$$

where,

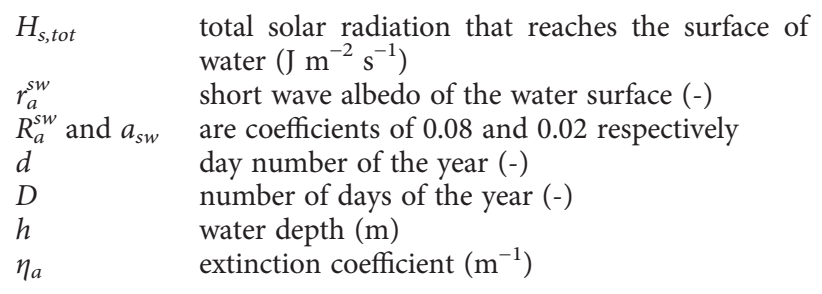

For Delft3D, the heat flux due to net short wave radiation was externally estimated based on Ollinger (1999) and prescribed as model input:

$$
\begin{gathered}
H_{s}=\left(1-r_{\text {dir }}\right) S_{\text {dir }}+\left(1-r_{\text {diff }}\right) S_{\text {diff }} \\
S_{\text {dir }}=(0.8-0.8 C) S, \\
S_{\text {diff }}=(0.2+0.8 C) S, \\
r_{\text {diff }}=0.05 C+(1-C) r_{\text {diff }, c .} .
\end{gathered}
$$

Delft3D also computes the absorption of the net short wave radiation into the water column using an exponential function of water depth and an extinction coefficient, so called "Secchi depth":

$$
H_{s}(h)=\frac{\gamma e^{-\gamma h}}{1-e^{-\gamma H}}(1-\beta) H_{s},
$$

where,

$r_{\text {dir }} \quad$ fraction of reflected direct solar radiation (-)

$S_{\text {dir }} \quad$ direct solar radiation $\left(\mathrm{J} \mathrm{m}^{-2} \mathrm{~s}^{-1}\right)$

$r_{\text {diff }} \quad$ fraction of reflection diffusivity (-)

$S_{\text {diff }}$ diffused short wave radiation $\left(\mathrm{J} \mathrm{m}^{-2} \mathrm{~s}^{-1}\right)$

$r_{\text {diff,c }}$ fraction of reflected diffusive short wave radiation for clear sky condition (-)

$S \quad$ solar radiation $\left(\mathrm{J} \mathrm{m}^{-2} \mathrm{~s}^{-1}\right)$

C cloud cover (-)

$\gamma \quad$ extinction coefficient $\left(\mathrm{m}^{-1}\right): 1.7 / H_{\text {Secchi }}$ where $H_{\text {Secchi }}$ is measured Secchi depth $(\mathrm{m})$

$H \quad$ total water depth (m)

$\beta \quad$ fraction of $\mathrm{Hs}$ absorbed at the water surface (0.06)

\section{Long wave radiation $\left(\mathrm{H}_{\mathrm{A}}\right)$}

In ELCOM, the long wave radiation is estimated using the following (Livingstone and Imboden 1989):

$$
\left(H_{A}-H_{W}\right)=\left(1-r_{a}\right) H_{W, \text { incident }}-\text { pdfilon }_{w} \sigma T_{w}^{4},
$$

where, 
$r_{a} \quad$ the albedo for long wave radiation ( 0.03 ; HendersonSellers 1986)

$T_{w} \quad$ water surface temperature $\left({ }^{\circ} \mathrm{C}\right)$

$H_{w, \text { incident }}$ incident solar wave radiation $\left(\mathrm{J} \mathrm{m}^{-2} \mathrm{~s}^{-1}\right.$; Iziomon et al. 2003)

$\sigma$ the Stefan-Boltzmann constant $\left(5.6697 \times 10^{-8} \mathrm{~W} \mathrm{~m}^{-2} \mathrm{~K}^{-4}\right)$

pdfilon $_{w} \quad$ emissivity of water (0.96)

Delft3D computes the effective back radiation from the water surface to atmosphere $\left(H_{w}-H_{A}\right.$ : net long wave radiation) using the Berliand's formula, which additionally takes into account actual vapour pressure compared to ELCOM. Furthermore, cloud cover is a fixed value during the simulation in the Murakami heat flux model (Murakami et al. 1985). The default value in Delft3D was adopted in this study as follows:

$$
\begin{aligned}
& \left(H_{A}-H_{W}\right)=-\varepsilon_{w} \sigma \bar{T}_{a}^{4}\left(0.39-0.058 \sqrt{e_{a}}\right)\left(1.0-0.65 C^{2}\right) \\
& \quad-4 \varepsilon_{w} \sigma \bar{T}_{a}^{3}\left(\bar{T}_{w}-\bar{T}_{a}\right),
\end{aligned}
$$$$
e_{a}=r_{h u m} 23.38 \exp \left(18.1-\frac{5303.3}{\bar{T}_{a}}\right)
$$

where,

$$
\begin{array}{ll}
e_{a} & \text { actual vapour pressure }(\mathrm{Pa}) \\
T_{a} & \text { air temperature }\left({ }^{\circ} \mathrm{C}\right) \\
r_{\text {hum }} & \text { relative humidity }(-) \\
\varepsilon_{w} & \text { emissivity factor }(0.985)
\end{array}
$$

\section{Latent heat flux $\left(\mathrm{H}_{\mathrm{E}}\right)$}

Latent heat flux in ELCOM is estimated based on Fischer et al. (1979), where actual vapour pressure $\left(e_{a}\right)$ is provided as a measured quantity:

$$
\begin{gathered}
H_{E}=-\min \left(0, \frac{0.622}{P} C_{L} \rho_{a} L_{E} U_{a}\left(e_{a}-e_{s}\left(T_{w}\right)\right) \Delta t\right), \\
\frac{\left(0.7859+0.03477 T_{a}\right)}{\left(1.0+0.00412 T_{a}\right)}, \\
e_{a}=r_{\text {hum }} .10 \\
e_{s}\left(T_{w}\right)=100 \exp \left[2.3026\left(\frac{7.5 T_{w}}{T_{w}+237.3}+0.758\right)\right],
\end{gathered}
$$

where,

$P \quad$ atmospheric pressure $(\mathrm{Pa})$
$C_{L} \quad$ latent heat transfer coefficient for wind speed at $10 \mathrm{~m}$ $\left(1.3 \times 10^{-3}\right)$

$\rho_{a} \quad$ density of air $\left(\mathrm{kg} \mathrm{m}^{-3}\right)$

$L_{E} \quad$ latent heat of evaporation of water $\left(2.453 \times 10^{6} \mathrm{~J} \mathrm{~kg}^{-1}\right)$

$U_{a} \quad$ wind speed at $10 \mathrm{~m}$ height $\left(\mathrm{m} \mathrm{s}^{-1}\right)$

$e_{s} \quad$ saturation vapour pressure $(\mathrm{Pa})$

$e_{a} \quad$ actual vapour pressure $(\mathrm{Pa})$

In Delft3D, latent heat flux is computed using the form of Dalton's law of mass transfer (Murakami et al. 1985). Actual vapour pressure $\left(e_{a}\right)$ is estimated using relative humidity and air temperature (equation A12):

$$
\begin{gathered}
H_{E}=L_{v} f\left(U_{a}\right)\left(e_{s}-e_{a}\right), \\
L_{v}=2.5 \times 10^{6}-2.3 \times 10^{3} T_{w}, \\
f\left(U_{10}\right)=c_{m u r} U_{a}, \\
e_{s}=23.38 \exp \left(18.1-\frac{5303.3}{\bar{T}_{w}}\right),
\end{gathered}
$$

where,

$L_{v} \quad$ latent heat of vaporisation $\left(\mathrm{J} \mathrm{kg}^{-1}\right)$

$c_{\text {mur }}$ Murakami constant $\left(1.2 \times 10^{-9}\right)$

\section{Sensible heat flux $\left(\mathrm{H}_{\mathrm{C}}\right)$}

ELCOM computes sensible heat flux from the water surface using the relation provided in Fischer et al. (1979):

$$
H_{c}=C_{s} \rho_{a} C_{P} U_{a}\left(T_{w}-T_{a}\right) \Delta t,
$$

where,

$C_{s} \quad$ sensible heat transfer coefficient for wind speed at $10 \mathrm{~m}$ height (-)

$C_{P} \quad$ specific heat of air at constant pressure $\left(1003 \mathrm{~J} \mathrm{~kg}^{-1} \mathrm{~K}^{-1}\right)$

$\Delta t \quad$ time period (s)

Delft3D assumes that the turbulent exchange of heat at the air-water interface equalshe turbulent exchange of mass. Thus, the convective heat flux can be related to the evaporative mass flux by the Bowen ratio (Deltares 2014):

$$
H_{c}=\gamma\left(\frac{T_{w}-T_{a}}{e_{s}-e_{a}}\right) H_{E}
$$

where,

$\gamma \quad$ Bowen's constant (0.66)

$e_{a}$ and $e_{s}$ are given in equations $\mathrm{A} 12$ and $\mathrm{A} 19$, respectively. 